\title{
3-D shear wave velocity structure of the crust and upper mantle in South China Sea and its surrounding regions by surface wave dispersion analysis
}

\author{
Hsin-Hung Wu ${ }^{1}$, Yi-Ben Tsai ${ }^{1}$, Tung-Yi Lee ${ }^{2}$, Ching-Hua Lo ${ }^{3}$, Chao-Hui Hsieh ${ }^{4}$ \\ and Dinh Van Toan ${ }^{5}$ \\ ${ }^{1}$ Institute of Geophysics, National Central University, Chung-Li, Taiwan (E-mail: wuhh@earth.ncu.edu.tw) \\ ${ }^{2}$ Department of Earth Sciences, National Taiwan Normal University, Taipei, Taiwan \\ ${ }^{3}$ Department of Earth Sciences, National Taiwan University, Taipei 106-17, Taiwan \\ ${ }^{4}$ Department of Civil and Ecological Engineering, I-Shou University, Kaohsiung County 840, Taiwan \\ ${ }^{5}$ Institute of Geological Sciences, National Center for Natural Sciences and Technology, Hanoi, Vietnam
}

Received 8 August 2003; accepted 20 August 2004

Key words: 3-D shear wave velocity structure, constrained block inversion method

\begin{abstract}
In this study, we construct a 3-D shear wave velocity structure of the crust and upper mantle in South China Sea and its surrounding regions by surface wave dispersion analysis. We use the multiple filter technique to calculate the group velocity dispersion curves of fundamental mode Rayleigh and Love waves with periods from $14 \mathrm{~s}$ to $120 \mathrm{~s}$ for earthquakes occurred around the Southeast Asia. We divide the study region $\left(80^{\circ} \mathrm{E}-140^{\circ} \mathrm{E}, 16^{\circ} \mathrm{S}-32^{\circ} \mathrm{N}\right)$ into $3^{\circ} \times 3^{\circ}$ blocks and use the constrained block inversion method to get the regionalized dispersion curve for each block. At some chosen periods, we put together laterally the regionalized group velocities from different blocks at the same period to get group velocity image maps. These maps show that there is significant heterogeneity in the group velocity of the study region. The dispersion curve of each block was then processed by surface wave inversion method to obtain the shear wave velocity structure. Finally, we put the shear wave velocity structures of all the blocks together to obtain the three-dimensional shear wave velocity structure of crust and upper mantle. The three-dimensional shear wave velocity structure shows that the shear wave velocity distribution in the crust and upper mantle of the South China Sea and its surrounding regions displays significant heterogeneity. There are significant differences among the crustal thickness, the lithospheric thickness and the shear wave velocity of the lid in upper mantle of different structure units. This study shows that the South China Sea Basin, southeast Sulu Sea Basin and Celebes Sea Basin have thinner crust. The thickness of crust in South China Sea Basin is 5-10 km; in Indochina is $25-40 \mathrm{~km}$; in Peninsular Malaysia is $30-35 \mathrm{~km}$; in Borneo is $30-35 \mathrm{~km}$; in Palawan is $35 \mathrm{~km}$; in the Philippine Islands is $30-35 \mathrm{~km}$, in Sunda Shelf is $30-35 \mathrm{~km}$, in Southeast China is $30-40 \mathrm{~km}$, in West Philippine Basin is 5$10 \mathrm{~km}$. The South China Sea Basin has a lithosphere with thickness of about $45-50 \mathrm{~km}$, and the shear wave velocity of its lid is about 4.3-4.7 km/s; Indochina has a lithosphere with thickness of about $55-70 \mathrm{~km}$, and the shear wave velocity of its lid is about $4.3-4.5 \mathrm{~km} / \mathrm{s}$; Borneo has a lithosphere with thickness of about $55-60 \mathrm{~km}$, and the shear wave velocity of its lid is about $4.1-$ $4.3 \mathrm{~km} / \mathrm{s}$; the Philippine Islands has a lithosphere with thickness of about $55-60 \mathrm{~km}$, and the shear wave velocity of its lid is about $4.2-4.3 \mathrm{~km} / \mathrm{s}$, West Philippine Basin has a lithosphere with thickness of about $50-55 \mathrm{~km}$, and the shear wave velocity of its lid is about $4.7-4.8 \mathrm{~km} / \mathrm{s}$, Sunda Self has a lithosphere with thickness of about $55-65 \mathrm{~km}$, and the shear wave velocity of its lid is about $4.3 \mathrm{~km} / \mathrm{s}$. The Red-River Fault Zone probably penetrates to a depth of at least $200 \mathrm{~km}$ and is plausibly the boundary between the South China Block and the Indosinia Block.
\end{abstract}

\section{Introduction}

The South China Sea and its surrounding regions are complex geologically and tectonically (Figure 1). This region is under the interactions of the Eurasian Plate, Philippine Sea Plate, Pacific Plate and Indo-Australian Plate. A 3-D shear wave velocity structure in the crust and upper mantle is important for understanding the tectonics of this region.

The South China Sea is one of the marginal seas of the West Pacific. It can be divided into three parts, the northern continental margin, the South China Sea Basin, and the southern continental margin. The South China Sea Basin is oceanic in nature and is bounded by the Sunda Shelf 


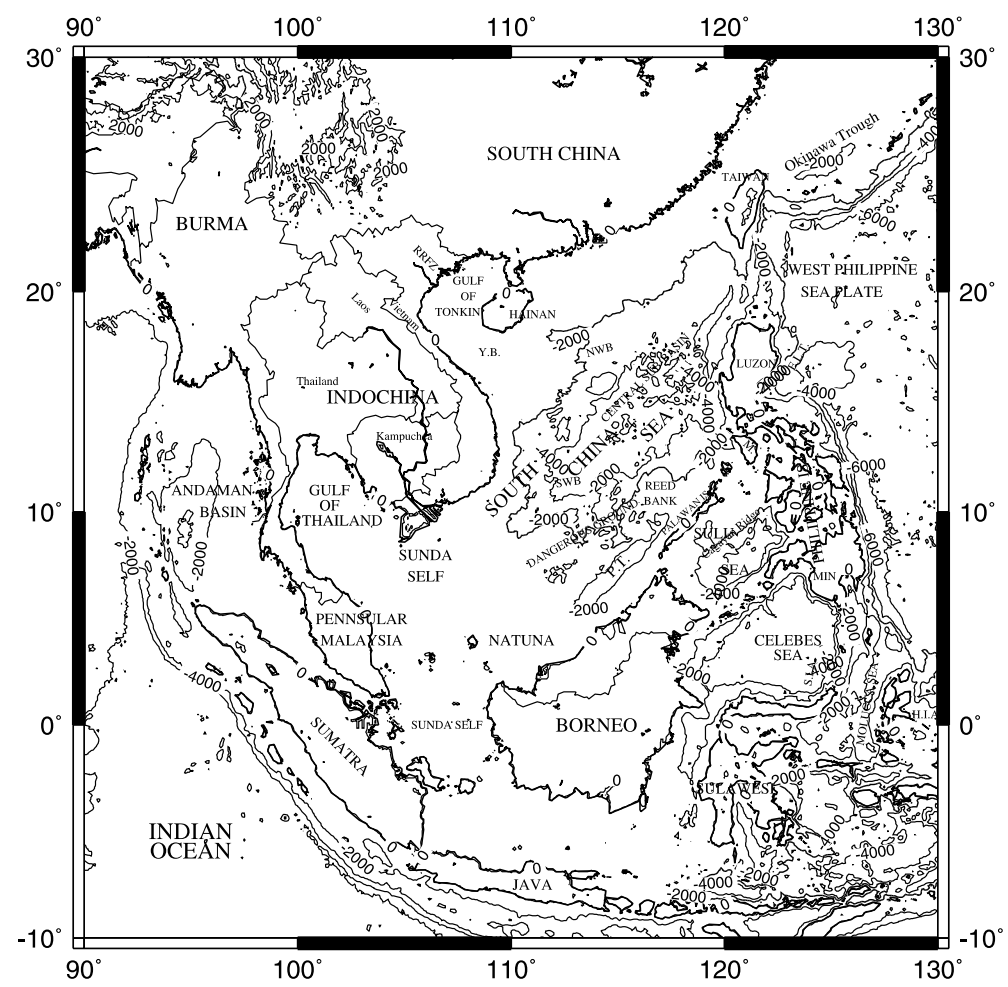

Figure 1. Topographic map of the South China Sea and its surrounding regions (contour interval at $2000 \mathrm{~m}$ ). NWB: Northwest Sub-basin, SWB: Southwest sub-basin, Y.B.: Yingge Basin, M.: Mindoro, E.L.T.: East Luzon Trough, MIN: Mindanao, H.I.A.: Hamahera Island Arc, S.I.A.: Sangihe Island Arc.

and northwest Borneo-Palawan Shelf in the south, by Luzon and Taiwan in the east, and by mainland Asia in the west and north. The South China Sea Basin can be subdivided geographically into the central sub-basin, the northwest sub-basin and the southwest sub-basin. The conspicuous (and unique) features of the basin are the broad, gently inclined side slopes off the Asian and Sunda shelves, the Palawan trough, and the Manila Trench (Ludwig et al., 1979). The South China Sea Basin was formed by seafloor spreading during 32-17 Ma (chron 11-5d) (Taylor and Hayes, 1980, 1983; Briais et al., 1993). Before the seafloor spreading of the South China Sea Basin, its northern continental margin was under tension. The onset of rifting of this proto-China margin was during the latest Cretaceous to Paleocene. In the southern continental margin, Reed Bank, Dangerous Ground, Mindoro and north Palawan are originally derived from the continental margin of South China. They are moved southeastwards to the present positions by the seafloor spreading of the South China Sea Basin.
The Red-River Fault Shear Zone is a conspicuous geological feature in our study region. It has been a major mid-Tertiary left-lateral fault boundary between South China and Indochina and has been undergone about $500-600 \mathrm{~km}$ of left-lateral motion during the opening of the South China Sea. The seafloor spreading of the South China Sea has been explained as an extrusion of Indochina relative to South China along this shear zone (Briais et al., 1993).

The crust of South China Sea Basin is oceanic in nature (Ludwig, 1970). Murauchi et al. (1973) showed that the crusts of southeast Sulu Sea Basin and of Celebes Sea Basin are also oceanic. Ludwig et al. (1979) measured the depth to the mantle at some profiles in the South China Sea Basin by using sonobuoy data. In the northern part of South China Sea, seismic profiles show that the crustal thickness thins from the continental shelf to deep sea (Nissen et al., 1995a; Schlüter et al.,1996; Kido et al., 2001; Qiu et al., 2001; Yan et al., 2001). For the whole area, the crustal thickness is calculated or conjectured 
mainly from gravity data (Liu et al., 1985; Chen and Lei, 1987) and sonobuoy data (Ludwig et al., 1979; Taylor and Hayes, 1983). Li and Mooney (1998) summarized the results of deep seismic sounding and gave the distribution map of crustal thickness in China. Cao et al. (2001) adopted surface waveform inversion with an equal block $\left(2^{\circ} \times 2^{\circ}\right)$ discretization in order to acquire the images of shear wave velocity structure at different depth (from surface to $430 \mathrm{~km}$ ) in the crust and upper mantle of the South China Sea and its surrounding region. Their results show significant difference in velocity, lithosphere and asthenosphere structure between South China Sea and its adjacent regions.

In this study, we present a 3-D shear wave velocity structure in the crust and upper mantle of the South China Sea and its surrounding region (from surface to $200 \mathrm{~km}$ ). Relative to the study of Cao et al. (2001), we use more ray paths in the study region to have a better coverage. For that we have especially installed two broadband stations in northern Vietnam. We use the group velocity dispersion characteristics of the fundamental mode Rayleigh and Love waves with periods from $14 \mathrm{~s}$ to $120 \mathrm{~s}$. We also used one station multiple filter technique to calculate the group velocity dispersion curves. Constrained block inversion method is used to get regionalized group velocities for each block such that we can get a smoother velocity model. Then, surface wave dispersion inversion is used to calculate 1-D shear wave velocity structure of each block. A 3-D shear wave velocity model is obtained by putting these 1-D models together laterally. This 3-D shear wave velocity structure will shed light on the tectonic structures of the Southeast Asia region.

\section{Data and method}

Data

The seismic surface wave data used in this study come from two sources: one is recorded by two broadband stations installed in North Vietnam by the Institute of Geophysics, National Central University, Taiwan; the other is recorded by the long-period seismographic stations of IRIS (Incorporated Research Institute for Seismology) (Figure 2). The seismic surface wave data were generated by events occurred around Southeast Asia (Figure 2). We extracted and analyzed the minor-arc surface waves. Because the minor-arc surface waves cover most of our target region, the interferences caused by the structures out of our target can be minimized. Locations of the 1252 events used in this study is shown in

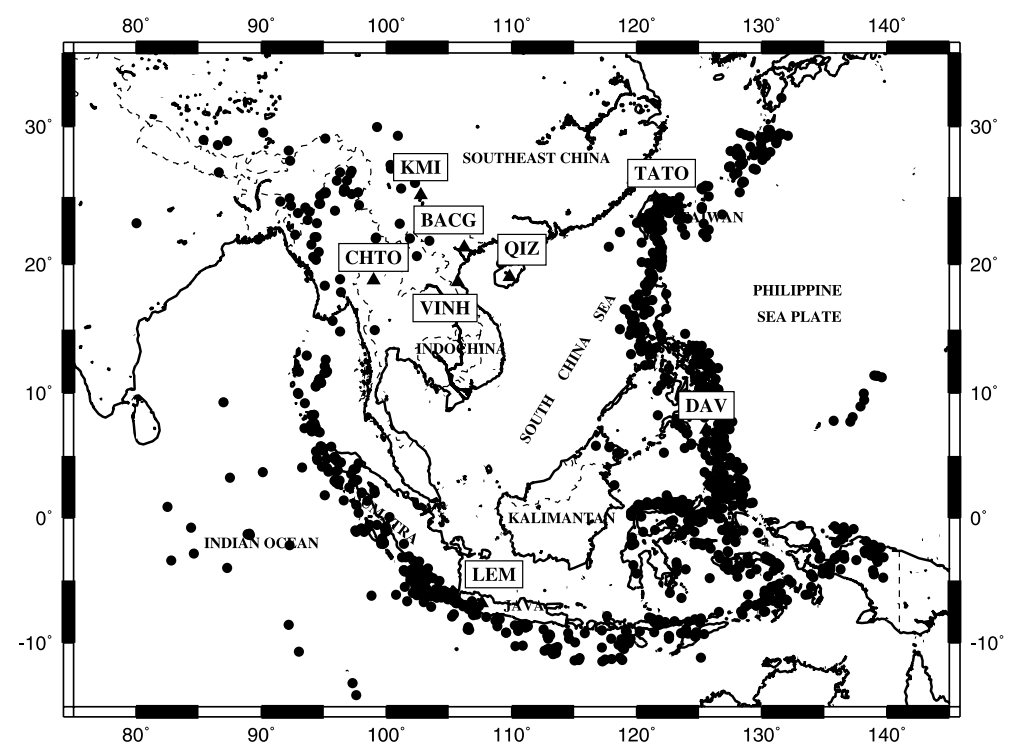

Figure 2. Locations of seismographic stations (triangle) and epicentral distribution of earthquakes (dots). For IRIS stations (KMI, TATO, QIZ, CHTO, DAV, LEM), the earthquakes span the years from 1982 to 2000; for broadband stations (BACG, VINH) in Vietnam, the earthquakes span the years from 1999 to 2002. 
Figure 2. Only the seismograms generated by earthquakes at depths shallower than $100 \mathrm{~km}$ were used, because the records of deeper events contains the higher modes which might contaminate fundamental modes.

\section{Group velocity determination by multiple filter technique}

We use the single station method to calculate the group velocities of the fundamental mode surface Rayleigh and Love waves by the Multiple Filter Technique (Dziewonski, 1969; Herrmann, 1973). We are able to obtain large amount of data by using single station method in order to have enough data for seismic tomography. The seismograms of three components at each station were deconvolved by the instrumental response to correct the instrumental delay and filtered in the frequency range from 0.008 to $0.1 \mathrm{~Hz}$. Then, the seismogram of vertical component is used to calculate the group velocity dispersion curve of fundamental mode Rayleigh wave. Both the seismograms of $\mathrm{E}-\mathrm{W}$ and $\mathrm{N}-\mathrm{S}$ components are rotated to obtain the transverse and radial components. The seismogram of the transverse component is then used to calculate the group velocity dispersion curve of fundamental mode Love wave. Examples are shown in Figure 3.

\section{Group velocity mapping with tomographic technique}

To study lateral heterogeneities of velocity structure in the crust and upper mantle of South China Sea region, the obtained group velocity dispersion curves are used to invert the group velocity distribution maps for different periods using 2-D tomographic technique. The block parameterization is adopted and each block size is $3^{\circ} \times 3^{\circ}$. This block inversion method used to calculate the regionalized group velocity in each block is based on the pure-path method (Knopoff, 1969), which is fundamental in the investigation of lateral variations of Earth structure by using seismic surface waves. It assumes that the seismic surface waves propagate along a great-circle path from seismic source to the seismographic station and each of the different structure units (blocks) along the path is homogeneous, and it neglects the refraction of seismic surface waves on every boundary between any two different structure units along the path. Thus, the travel time of seismic surface wave from source to the seismographic station is equal to the sum of travel times which the seismic surface wave propagate through each of the different structure units along the path from source to the recording station. It can be expressed as

$$
t_{i}(T)=\frac{L_{i}}{V_{0 i}}=\sum_{j=1}^{N} \frac{L_{i j}}{V_{j}(T)},
$$

where $t_{i}(T)$ is the observed travel time for the $i$ th wave path at period $T, L_{i}$ is the epicentral distance for the $i$ th wave path, $i=1,2, \ldots, M, V_{0 i}$ is the observed group velocity for the $i$ th wave path at period $T, L_{i j}$ is the distance traveled by the $i$ th wave path within the $j$ th block, $V_{j}(T)$ is the regionalized group velocity in the $j$ th block at period $T, N$ is the total number of blocks in the study region, $M$ is the total number of ray paths.

In this study we divided the study region $\left(80^{\circ} \mathrm{E}-140^{\circ} \mathrm{E}, \quad 16^{\circ} \mathrm{S}-32^{\circ} \mathrm{N}\right)$ into $N$ blocks (Figure $4, N=242$ ) and have $M$ ray paths (Figure 5, $M=1184-2385$ ) to cover these blocks. For each of the ray paths, i.e. the $i$ th ray path, we calculate the group velocity $V_{0 i}$, the epicentral distance $L_{i}$ and the distance $L_{i j}$ within each of the blocks traversed by this ray path. From these data, we used the block inversion method to be described below to calculate the regionalized group velocity at period $T$ for each of the blocks. Thus, we can get the regionalized dispersion curve for each of the blocks in our study region.

Equation (3.1) is a linear inversion problem, it can be expressed in matrix form as

$$
A x=b,
$$

where

$$
A=\left[\begin{array}{cccc}
L_{11} & L_{12} & \cdots & L_{1 N} \\
L_{21} & L_{22} & \cdots & L_{2 N} \\
\cdots & \cdots & \cdots & \cdots \\
L_{M 1} & L_{M 2} & \cdots & L_{M N}
\end{array}\right] .
$$

Matrix $A$ is the kernel matrix. Its elements are the distances within each of the blocks traversed by each of the ray paths. If there are $M$ $(i=1,2, \ldots, M)$ ray paths and $N(j=1,2, \ldots, N)$ blocks, then the order of $A$ is $M \times N$.

Vector $b$ consists of the observed travel time for each of the ray paths and is given by 

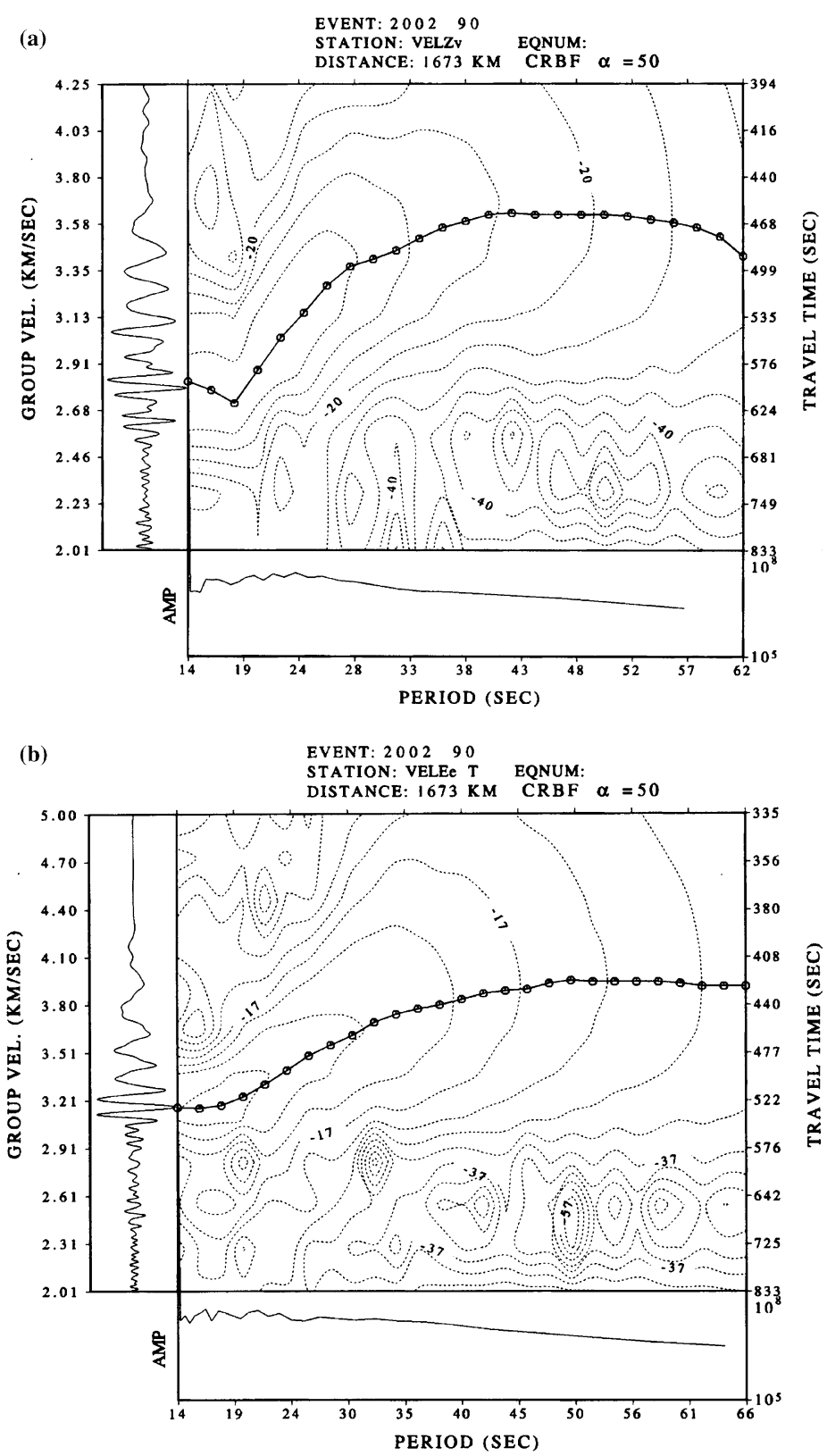

Figure 3. (a) Group velocity dispersion curve of Rayleigh wave obtained by using the multiple filter technique (MFT) for station BACG. Trace with circles shows group velocities chosen at different periods. They are maximums of the energy contours. Left column shows group velocity, right column shows travel time. (b) Group velocity dispersion curve of Love wave obtained by the multiple filter technique for station BACG. Others are the same as in (a).

$$
b=\left[\begin{array}{c}
t_{1}(T) \\
t_{2}(T) \\
\cdots \\
t_{M}(T)
\end{array}\right]=\left[\begin{array}{c}
L_{1} / V_{o 1}(T) \\
L_{2} / V_{o 2}(T) \\
\ldots \\
L_{M} / V_{o M}(T)
\end{array}\right] .
$$

blocks and is called the slowness vector and is given by

$$
x=\left[\begin{array}{c}
\frac{1}{V_{1}(T)} \\
\frac{1}{V_{2}(T)} \\
\cdots \\
\frac{1}{V_{N}(T)}
\end{array}\right] .
$$




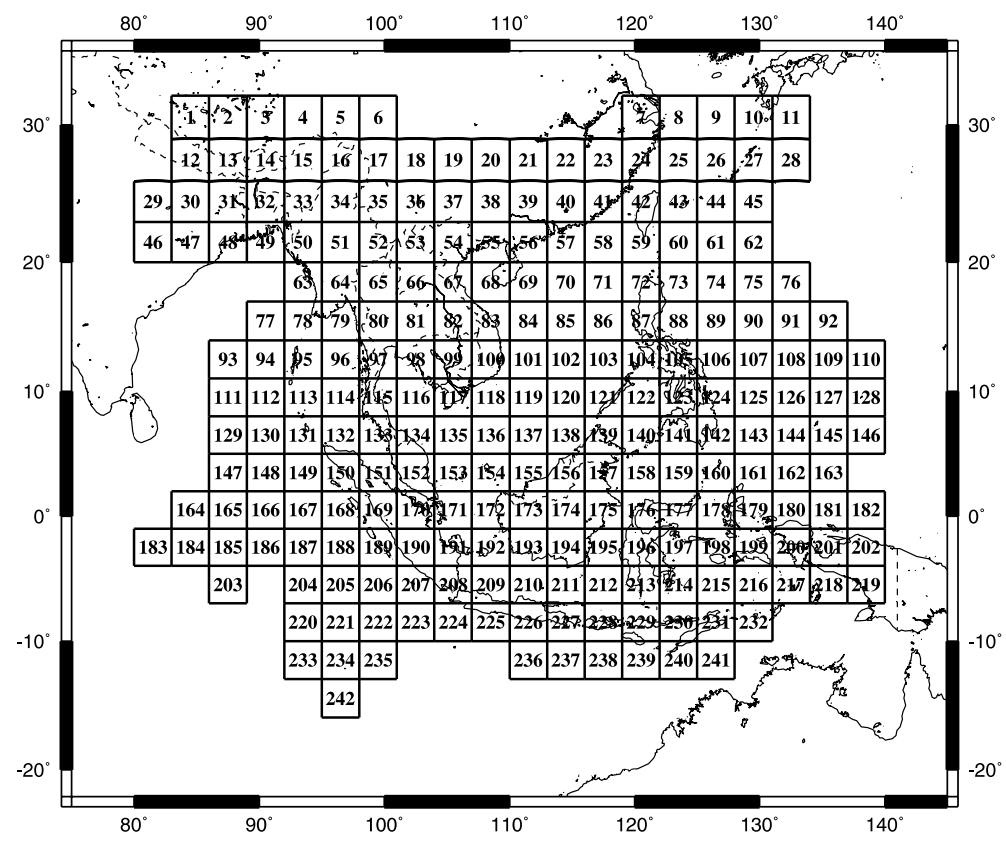

Figure 4. The study region from $80^{\circ} \mathrm{E}-140^{\circ} \mathrm{E}$ and $16^{\circ} \mathrm{S}-32^{\circ} \mathrm{N}$ is divided into $3^{\circ} \times 3^{\circ}$ blocks. Total number of blocks is 242 .

To solve Equation (3.2) and get a smooth model, we used the constrained linear inversion method. That is, the smoothness or roughness inversion method (Twomey, 1977; Constable et al., 1987) and simple spatial smoothness constraints, which involves 2-D Laplacian, are introduced in this study by assuming that the slowness of each of the blocks is correlated to that of its surrounding eight blocks. We also assume that each central block has a weight of 5, and each of the blocks located to the north, south, west and east of the central block has weight of 1 and each of the blocks located to the northwest, northeast, southwest and southeast of the central block has weight of 0.25 . Then the relationship can be expressed as follows:

$$
\begin{aligned}
& -m(i-1, j)-m(i, j-1)-0.25 m(i-1, j-1) \\
& -0.25 m(i+1, j-1)+5 m(i, j)-m(i+1, j) \\
& -m(i, j+1)-0.25 m(i-1, j+1) \\
& -0.25 m(i+1, j+1)=0
\end{aligned}
$$

where $m(i, j)$ is the slowness of a central block, $m(i-1, j), m(i+1, j), m(i, j-1)$, and $m(i, j+1)$ are slownesses of blocks located to the north, south, west and east of the central block, respec- tively, $\quad m(i-1, j-1), \quad m(i-1, j+1), \quad m(i+1$, $j-1)$, and $m(i+1, j+1)$ are slownesses of blocks located to the northwest, northeast, southwest and southeast of the central block, respectively.

By choosing each of the $N$ blocks in the study region as a central block, we get a corresponding equation as (3.3), thus we get a system of $N$ equations. It can be expressed in matrix form as $D x=0$, where $D$ is a matrix made up of the coefficients of the system of $N$ equations, and is called the roughness matrix, and $x$ is the slowness vector as defined before. $D x$ is called the roughness of the solution of Equation (3.2), and the length of the roughness is given by:

$$
L=(D x)^{T}(D x)=x^{T} D^{T} D x,
$$

where $(D x)^{T}, x^{T}, D^{T}$ are transposes of matrices $D x, x$, and $D$, respectively.

Then, we used Lagrangian multiplier, $\lambda^{2}$, to form the function $\Phi$,

$$
\Phi=E+\lambda^{2} L=e^{T} e+\lambda^{2}\left(x^{T} D^{T} D x\right),
$$

where $e_{i}=t_{i}^{o b s}-t_{i}^{p r e}$, it is the difference between the observed and the predicted travel time, matrix $e=\left(e_{1}, e_{2}, \ldots, e_{N}\right)$ and $e^{T}$ is the transpose of $e$, and $E=\sum_{i=1}^{M} e_{i}^{2}$, it is the sum of 

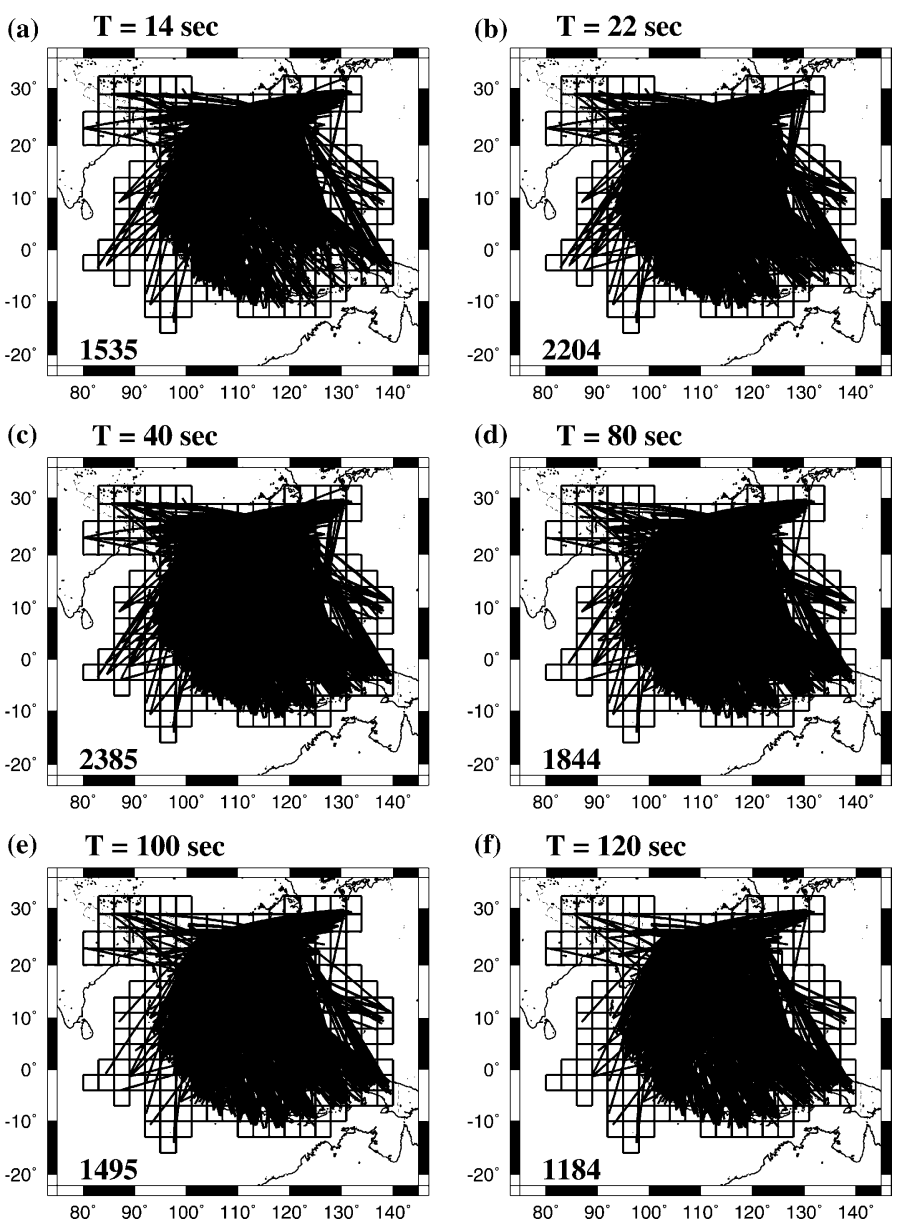

Figure 5. The distribution of ray paths for different period (T) of Rayleigh wave, the number of total ray paths is shown in lower-left corner.

squared prediction errors. Then, we try to minimize $\Phi$ to get the estimate of the slowness vector, $x$. This is a constrained linear inversion, and the estimate $x^{e s t}$ of the slowness vector $x$ is given by:

$$
\begin{aligned}
x^{e s t} & =\left(A^{T} A+\lambda^{2} D^{T} D\right)^{-1} A^{T} b \\
& \equiv A^{-g} b,
\end{aligned}
$$

where $A^{-g}=\left(A^{T} A+\lambda^{2} D^{T} D\right)^{-1} A^{T}$ is called generalized inverse matrix and is solved by $S V D$ (Singular Value Decomposition) (Menke, 1984). The Lagrangian Multiplier, $\lambda^{2}$, is used to constrain the relative importance of $E$ and $L$ in the determination of $x^{e s t}$.

The resolution matrix $R$ and the covariance matrix $C$ are given as follows:

$$
\begin{aligned}
R & =A^{-g} A=\left(A^{T} A+\lambda^{2} D^{T} D\right)^{-1} A^{T} A \\
C & =A^{-g}\left(A^{-g}\right)^{T} \\
& =\left(A^{T} A+\lambda^{2} D^{T} D\right)^{-1} A^{T} A\left(A^{T} A+\lambda^{2} D^{T} D\right)^{-1} .
\end{aligned}
$$

The standard deviation of the estimate of slowness, $\sigma_{s}$, can be calculated by (Ewing and Mitchell, 1970)

$$
\left(\sigma_{s}\right)_{i}=\left[\frac{E}{M-N} C_{i i}\right]^{1 / 2},
$$

where $i$ represents the $i$ th block, $C_{i i}$ is the $i$ th element of the main diagonal of $C, E$ is the sum of squares of the prediction errors, $M$ the total 
number of observations, and $N$ is the number of total blocks. We can calculate the standard deviation of the regionalized group velocity, $\sigma_{v}$, from the standard deviation of the slowness, $\sigma_{s}$, (Nishimura and Forsyth, 1985) as

$$
\left(\sigma_{v}\right)_{i}=\left[\frac{\left(\sigma_{s}\right)_{i}}{\left(x^{e s t}\right)^{2}}\right]^{1 / 2}
$$

where $i$ represents the $i$ th block.

In Equation (3.5), the damping parameter, $\lambda^{2}$, decide the trade-off between the length of error, $E$, and the length of roughness, $L$. In this study, we take $\lambda^{2}=\operatorname{Tr}\left(A^{T} A\right) / \operatorname{Tr}\left(D^{T} D\right)$ as the initial value. Then, we require that the root mean square of prediction error is not too large, the standard deviation of the solution of slowness vector is small, and the resolution matrix is stable. Finally, we check whether the estimate of slowness vector is reasonable in order to set $\lambda^{2}$ to a proper value.

The resolution of the estimate of slowness vector is interpreted by the resolution matrix $R$ through the relation $x^{e s t}=R x^{\text {true }}$, where $x^{\text {true }}$ is the true slowness vector. If $R$ is an identity matrix of order $N$, then the estimate of slowness can completely resolve the true slowness vector. A good resolution is that the element in $R$ corresponding to the chosen block has largest value and elements corresponding to blocks adjacent to the chosen block have nonzero values and all other elements have zero values.

Because the number of model parameter is large, it is not easy to show the resolution matrix for all the blocks in a figure. So, we use the resolving length to show the resolution of the estimate of our slowness vector (Figure 6). The resolving length for the $i$ th block, $J_{i}$, is given by (Liu et al., 1990) as

$$
J_{i}=\sum_{k=1}^{n}\left(\frac{s_{i k}}{\left|s_{i}\right|}\right)^{2} W_{i k},
$$

where $i$ means the $i$ th block, $\left|s_{i}\right|$ is the length of the $i$ th row of resolution matrix, $s_{i k}$ is the $i k$ th element of the resolution matrix, and $W_{i k}$ is the distance between the centers of $i$ th and $k$ th block. When the resolution matrix is nearer to the identity matrix, each $J_{i}$ is smaller, then the resolution of each block is better. In this study, the size of each block is $3^{\circ} \times 3^{\circ}$, thus, if the resolving length of a block is smaller than $330 \mathrm{~km}$, this means that the contamination on this block from other blocks is small, that is the result of this block can resolve itself, then the resolution of this block is good. The smaller the resolving length, the better the resolution of the block.

In this study, we divided the study area $\left(80^{\circ} \mathrm{E}-140^{\circ} \mathrm{E}, 16^{\circ} \mathrm{S}-32^{\circ} \mathrm{N}\right)$ into 242 blocks each with an area of $3^{\circ} \times 3^{\circ}$ as shown in Figure 4. Then we used the data set of the above calculated group velocity dispersion curves of fundamental mode Rayleigh and Love waves and the block inversion method described above to find the regionalized group velocity dispersion curve for each of the blocks.

\section{Calculation of shear wave velocity structure}

The group velocity dispersion curve for each block obtained above was inverted following the method of Herrmann (1991) for 1-D seismic shear wave velocity structure where a laterally homogeneous structure is assumed for each block. This inversion was operated for each block independently from one another. These 1D structures obtained for every block were arranged laterally. This arranged 1-D structures can be regarded as a 3-D structure in the South China Sea and its surrounding region.

The relationship between the surface wave group velocity dispersion and the shear wave velocity structure of the crust and upper mantle is nonlinear. In order to invert the dispersion curve to get the shear wave velocity structure, we need to have a reasonable initial model. We can express the relationship by Herrmann (1991)

$$
\begin{aligned}
U_{i}= & V_{i}\left(M_{0}\right)+\sum_{j}\left(\left.\frac{\partial V_{i}}{\partial M_{j}}\right|_{M_{0}} \Delta M_{j}\right) \\
& + \text { higher-order terms, }
\end{aligned}
$$

where $U_{i}$ is the observation of group velocity at $i$ th period, $M_{0}$ is the initial shear wave velocity model, $V_{i}\left(M_{0}\right)$ is the calculated group velocity with respect to the initial model at $i$ th period., $\left.\frac{\partial V_{i}}{\partial M_{j}}\right|_{M_{0}}$ the partial derivative of the group velocity 

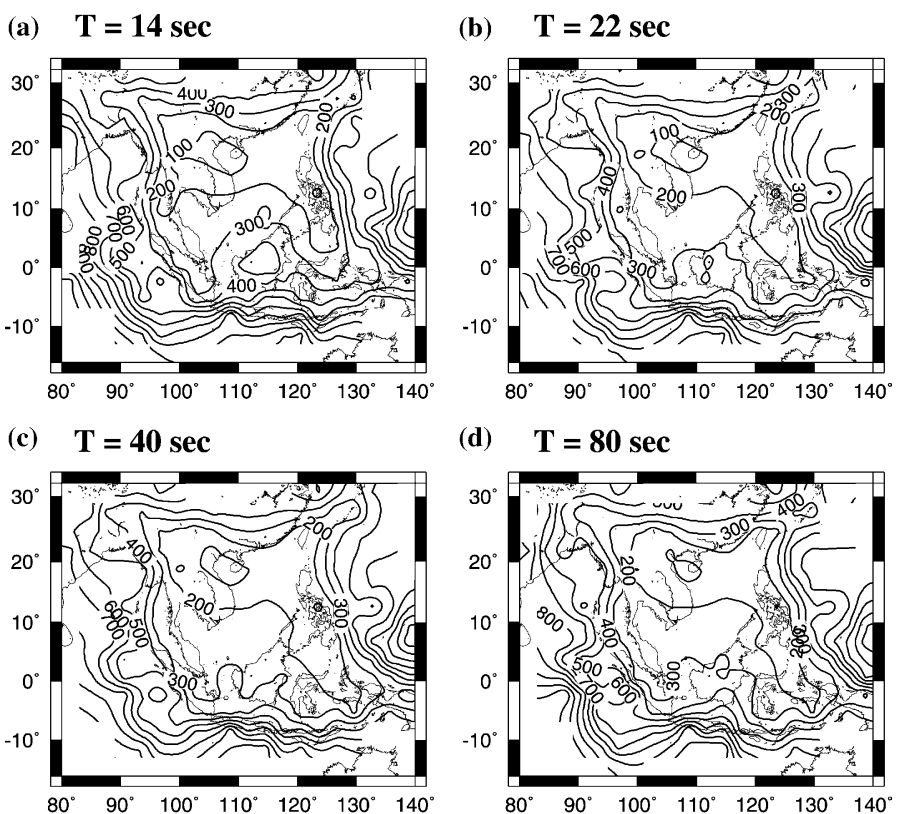

(d) $\mathbf{T}=80 \mathrm{sec}$
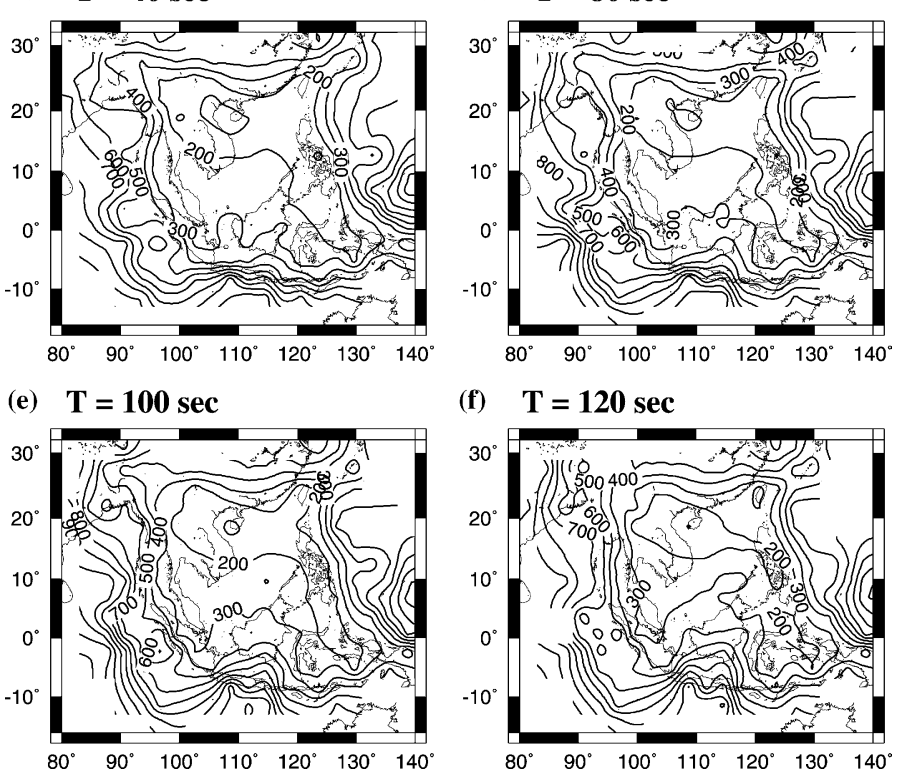

Figure 6. The resolution length $(\mathrm{km})$ for regionalized group velocity of Rayleigh waves at different periods $(\mathrm{T})$.

at $i$ th period to the $j$ th model parameter and it is calculated with respect to the initial model $M_{0}$, and $\Delta M_{j}$ is the amount of change in the $j$ th model parameter.

If the initial model approaches the real structure, the higher-order terms can be neglected. Thus, we can get

$$
\Delta U_{i}=U_{i}-V_{i}\left(M_{0}\right)=\sum_{j}\left(\left.\frac{\partial V_{i}}{\partial M_{j}}\right|_{M_{0}} \Delta M_{j}\right),
$$

where $\Delta U_{i}$ is the difference between the observed group velocity and the calculated group velocity and $\Delta M_{j}$ is the amount of change in the $j$ th model parameter. $\Delta U_{i}$ and $\Delta M_{j}$ has linear relationship. If we have observations of group velocity in $N$ periods and there are $L$ model parameters, then we have a system of $N$ equations, which is expressed in matrix form as

$$
\left.\left[\begin{array}{cccc}
\frac{\partial V_{1}}{\partial M_{1}} & \frac{\partial V_{1}}{\partial M_{2}} & \cdots & \frac{\partial V_{1}}{\partial M_{L}} \\
\frac{\partial V_{2}}{\partial M_{1}} & \frac{\partial V_{2}}{\partial M_{2}} & \cdots & \frac{\partial V_{2}}{\partial M_{L}} \\
\vdots & \vdots & \vdots & \vdots \\
\frac{\partial V_{N}}{\partial M_{1}} & \frac{\partial V_{N}}{\partial M_{2}} & \cdots & \frac{\partial V_{N}}{\partial M_{L}}
\end{array}\right]\right|_{M_{o}}\left[\begin{array}{c}
\Delta M_{1} \\
\Delta M_{2} \\
\vdots \\
\Delta M_{L}
\end{array}\right]=\left[\begin{array}{c}
\Delta U_{1} \\
\Delta U_{2} \\
\vdots \\
\Delta U_{N}
\end{array}\right] .
$$

The system of equation above can also be expressed in matrix form as $P \Delta M=\Delta U$. Where $P$ matrix is made of the partial derivatives of group velocity to the model parameter, the calculation is done by using the algorithm of Rodi et al. (1975).

$\Delta M$ is a column vector of variations of the shear wave velocity model and $\Delta U$ is a column vector of differences in observed and calculated group velocities. From this equation, we can start a linear iteration to progressively modify the initial model to get the final model. In this 
(a) $\mathrm{T}=16 \mathrm{sec}$

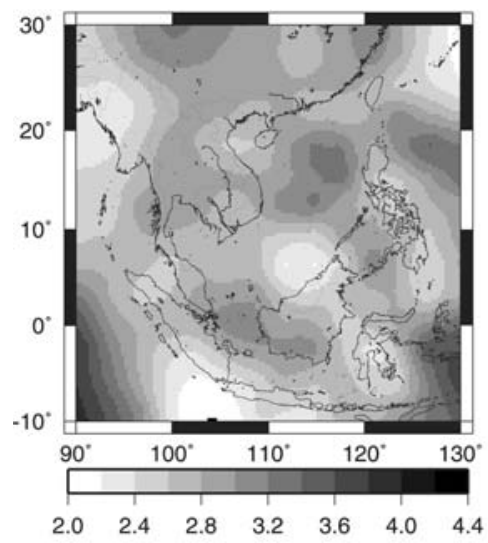

Group Velocity of Rayleigh Wave $(\mathrm{km} / \mathrm{sec})$

(b) $\mathrm{T}=\mathbf{4 0} \mathrm{sec}$

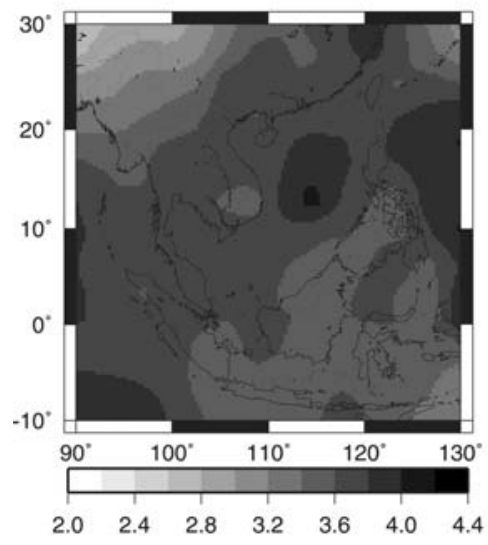

Group Velocity of Rayleigh Wave $(\mathrm{km} / \mathrm{sec})$ (c) $\mathrm{T}=\mathbf{8 0} \mathrm{sec}$

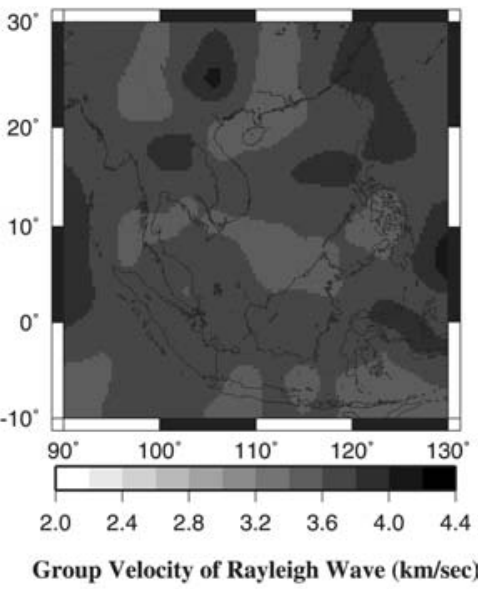

(d) $\mathrm{T}=\mathbf{1 0 0 \mathrm { sec }}$

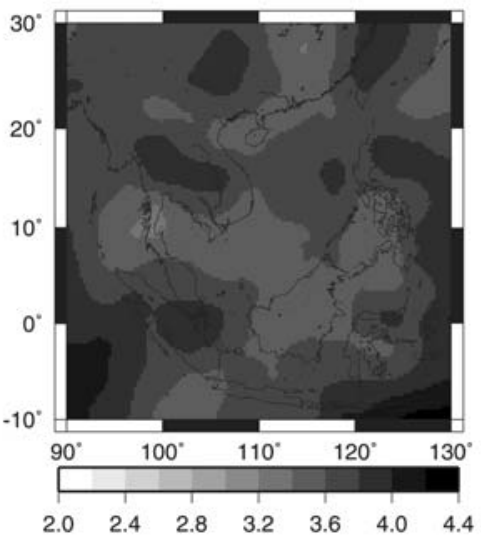

Group Velocity of Rayleigh Wave $(\mathrm{km} / \mathrm{sec})$

Figure 7. The distribution of group velocity of fundamental mode Rayleigh wave at different periods (T).

inversion, we use the constrained linear inversion method (Constable et al., 1987) in order to minimize the side effect of initial model on the final model.

In order to minimize the influence of the initial model on the resulting model, we use a homogeneous initial model with shear wave velocity of $4.3 \mathrm{~km} / \mathrm{s}$ for every layer in the model. This initial model has a half space and above which there are 49 layers within $350 \mathrm{~km}$ for inverting data of Rayleigh and Love waves together.

Taking into account the effect of sea water on the final structure of a block, we fix a water layer for the initial model with a layer thickness according to the average of bathymetries within the block when this is necessary for that block.
From the above 3-D shear wave velocity structure, we construct the lateral variation of crustal thickness in the South China Sea and its surrounding regions by assuming $3.95 \mathrm{~km} / \mathrm{s}$ as the $S_{n}$ velocity in order to find the thickness of crust for each block. The thickness of the surface water layer is excluded. We also tried $4.00 \mathrm{~km} / \mathrm{s}$ and $4.05 \mathrm{~km} / \mathrm{s}$ for $S_{n}$ velocity respectively, but we find that we get more reasonable solution for $S_{\mathrm{n}}=3.95 \mathrm{~km} / \mathrm{s}$. The Moho is typically defined as the horizon below which $\mathrm{P}$ wave velocities are larger than $7.6 \mathrm{~km} / \mathrm{s}$ (Steinhart, 1967). Low $P_{n}$ velocities $(7.6-7.8 \mathrm{~km} / \mathrm{s}$ ) are usually restricted to region of thin $(<35 \mathrm{~km})$ crust with moderate to high heat flow, and high $P_{n}$ velocities correlate with thicker crust $(>40 \mathrm{~km})$ with low heat flow (i.e. stable continental interior). 
(a) $\mathrm{T}=\mathbf{2 0} \mathrm{sec}$

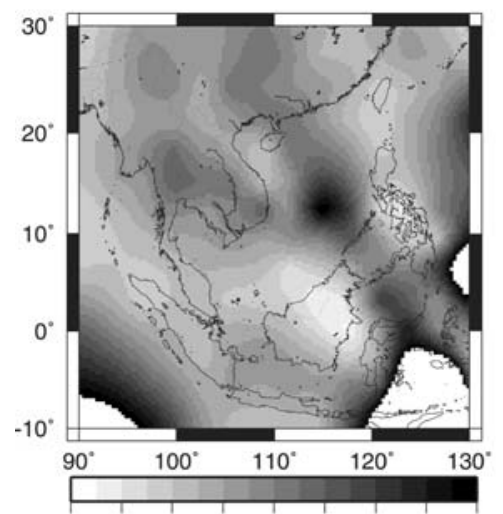

$\begin{array}{lllllllll}2.0 & 2.4 & 2.8 & 3.2 & 3.6 & 4.0 & 4.4 & 4.8 & 5.2\end{array}$ Group Velocity of Love Wave $(\mathrm{km} / \mathrm{sec})$

(b) $\mathrm{T}=40 \mathrm{sec}$

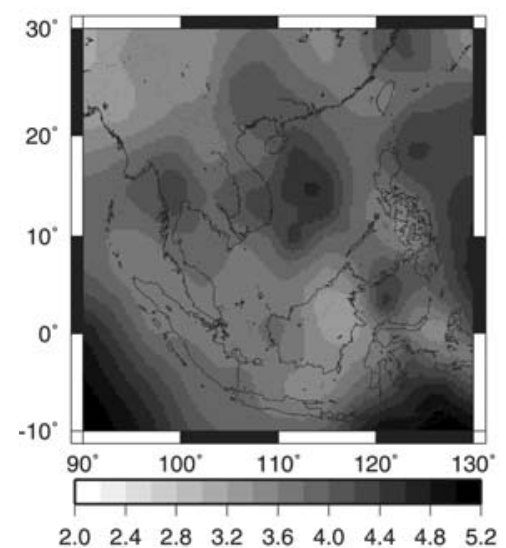

Group Velocity of Love Wave $(\mathrm{km} / \mathrm{sec})$ (c) $\mathrm{T}=80 \mathrm{sec}$

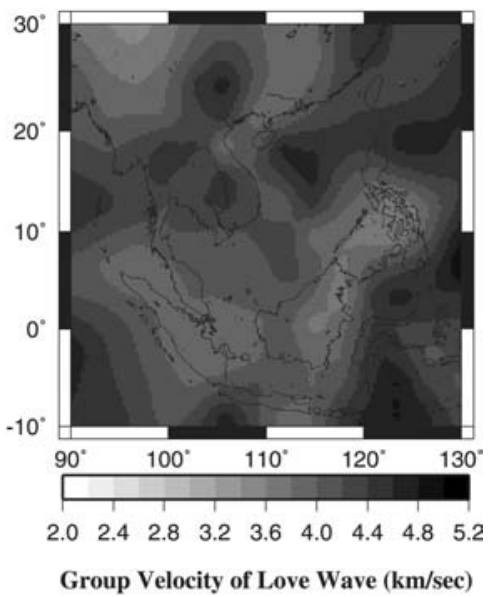

(d) $\mathrm{T}=100 \mathrm{sec}$

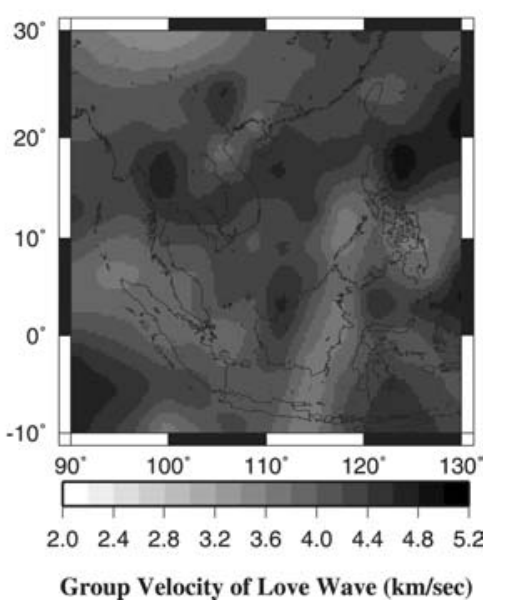

Figure 8. The distribution of group velocity of fundamental mode Love wave at different periods (T).

So, in this study, we take $S_{n}=3.95 \mathrm{~km} / \mathrm{s}$ to define the crustal thickness.

We also construct a distribution of the thickness of lithospheres in the South China Sea and surrounding regions. We assume the bottom of the lithosphere has the maximum shear wave velocity in the upper mantle. Then, we find the depth where this maximum shear wave velocity occurred. The depth found is taken as the thickness of this lithosphere. The thickness thus obtained is less than it should be, because it is plausible for the bottom of a lithosphere to locate at the depth where the shear wave velocity decreases most rapidly with depth (Cao et al., 2001).

\section{Results}

Figure 4 shows the distribution of $3^{\circ} \times 3^{\circ}$ blocks used. Figure 5 shows the path coverage of the tomographic analysis for Rayleigh wave. Since the paths of propagation cover most of the South China Sea region, our results are expected to have good resolution in the South China Sea and its surrounding regions. Figures $6 \mathrm{a}-\mathrm{f}$ show the distribution of resolving length of our tomographic analysis for Rayleigh wave at the period of $14,22,40,80,100$, and $120 \mathrm{~s}$, respectively. Most of the target area has resolving length less than $330 \mathrm{~km}$, so most of the target region have good resolution, especially in the South China 
(a) Depth at $20 \mathrm{~km}$

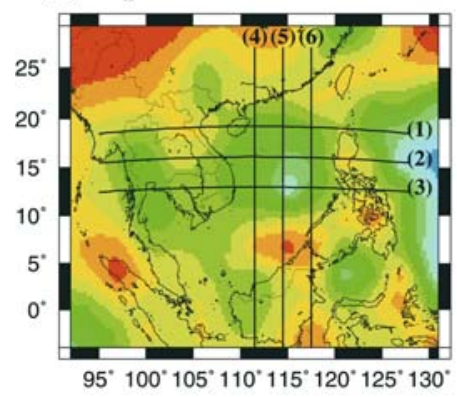

(b) Depth at $30 \mathrm{~km}$

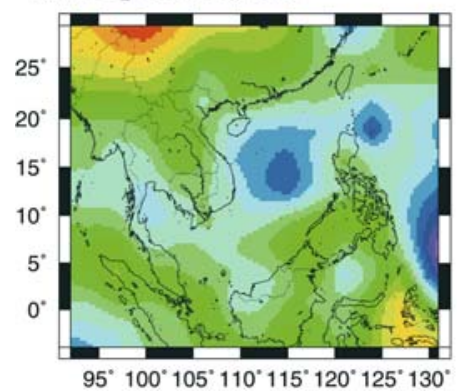

(c) Depth at $60 \mathrm{~km}$

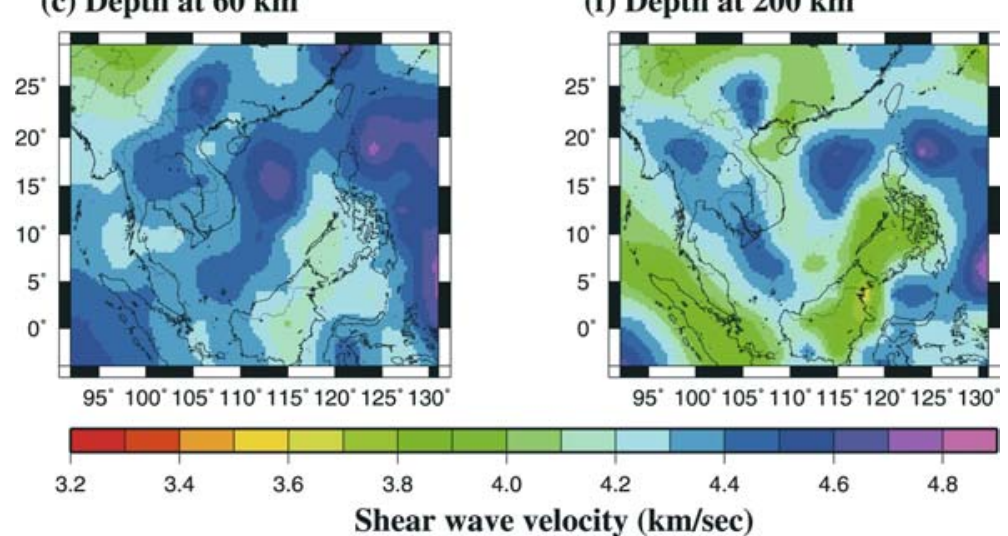

(d) Depth at $85 \mathrm{~km}$

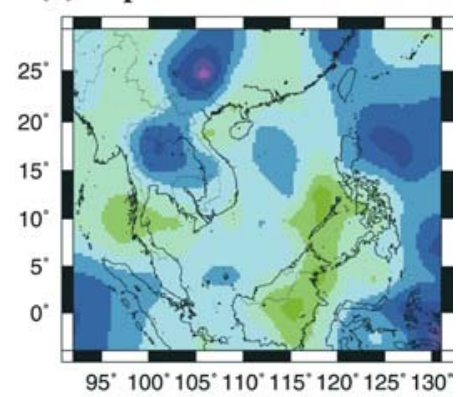

(e) Depth at $120 \mathrm{~km}$

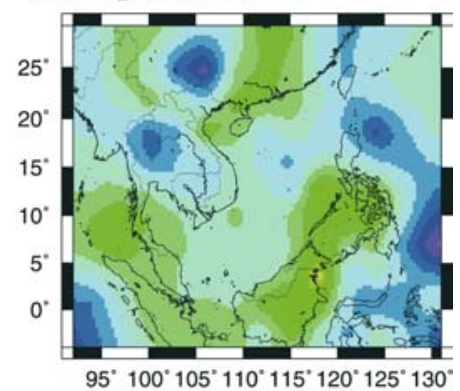

(f) Depth at $200 \mathrm{~km}$

Figure 9. Distribution of shear wave velocity at different depths. Shear wave velocity is obtained by inverting regionalized group velocity of fundamental mode Rayleigh and Love waves together.

Sea Basin, Indochina, Borneo, Sulu Sea Basin, Celebes Sea Basin, the Philippine Islands and the Molucca Sea.

Figures $7 \mathrm{a}-\mathrm{d}$ show the group velocity distribution of the Rayleigh waves at the periods of $16,40,80$ and $100 \mathrm{~s}$, respectively.

Figure 7a shows the group velocity distribution of the Rayleigh wave for the period of $16 \mathrm{~s}$. In this map, higher group velocity shows up in the South China Sea Basin, in West Philippine Sea Plate, in southeastern Sulu Sea Basin, in Molucca
Sea, in the area of southern Thailand, northern part of the Gulf of Thailand and the northeastern part of Andaman Sea, and in the Sunda Shelf to the north of Java. Lower group velocity shows up in the northeastern part of Borneo, in the Palawan Trough and Sunda Shelf, in the Gulf of Tonkin, in western and southern Sulawesi and in the Philippine Island, and in Okinawa Trough.

Figure $7 b$ shows the group velocity distribution map of Rayleigh wave for the period of 40 s. Higher group velocity shows up in the 
South China Sea Basin, in Luzon, in the West Philippine Sea Plate, in Eastmal (eastern Peninsular Malaysia ) and Sunda Shelf, in the area to the northeast of Red River Fault Zone in north Vietnam, in Celebes Sea Basin, also in the southwestern part of Thailand. Lower group velocity shows up in eastern Borneo, in Palawan Trough, in northwest Sulu Sea Basin, in central Philippine Islands, in Burma.

Figure 7c shows the group velocity distribution map of Rayleigh wave for the period of $80 \mathrm{~s}$. Higher group velocity shows up in the South China Sea Basin, in Luzon, in the West Philippine Sea Plate, in Celebes Sea Basin, in the northern arm of Sulawesi, in Molucca Sea, in west Borneo, in Sunda Shelf to the west of Natuna, in central Thailand, in the area to the north of Red River Fault Zone in north Vietnam. Lower group velocity shows up in northeastern Borneo, in Palawan Trough, in northwest Sulu Sea Basin, in central Philippine Islands, in the Gulf of Tonkin and Hainan, and in northern Burma.

Figure $7 \mathrm{~d}$ shows the group velocity distribution map of Rayleigh wave for the period of 100 s. Higher group velocity shows up in the South China Sea Basin, in Luzon, in West Phillipine Sea Plate, in most part of Indochina, in the area of China to the north of Red River Fault zone in Vietnam, in southeastern Celebes Sea Basin, in the northern arm of Sulawesi and in the Molucca Sea. Lower group velocity shows up in the northeastern part of Borneo and the Palawan Trough, in Sulu Sea basin, in northern and southern margin of South China Sea, and in central Philippine Islands.

Figures 8a-d show the group velocity distribution of the Love waves at the periods of 20, 40,80 and $100 \mathrm{~s}$, respectively. Figure $8 \mathrm{a}$ shows the group velocity distribution of the Love wave for the period of $20 \mathrm{~s}$. In this map, higher group velocity shows up in the South China Sea Basin, in West Philippine Sea Plate, in the Celebes Sea Basin, in the southeastern part of Sulu Sea Basin, in most area of Indochina, in the area of China to the northeast of Red-River Fault Zone in Vietnam. Lower group velocity shows up in the area from Taiwan to the Philippine Island, in the northeastern part of Borneo and in the Palawan Trough, in Yingge Depression Basin located to the south of Hainan and in northern Sumatra.
Figure $8 \mathrm{~b}$ shows the group velocity distribution map of Love wave for the period of $40 \mathrm{~s}$. Higher group velocity shows up in the South China Sea Basin, in northern Luzon, in the West Philippine Sea Plate, in the southeastern part of Sulu Sea Basin, in Celebes Sea Basin, in the area to the northeast of Red-River Fault Zone in north Vietnam, also in most of Indochina, Lower group velocity shows up in most of Borneo, in Palawan Trough, in central Philippine Islands, in the northern part of Burma and in northern Sumatra.

Figure $8 \mathrm{c}$ shows the group velocity distribution map of Love wave for the period of $80 \mathrm{~s}$. Higher group velocity shows up in the South China Sea Basin, in northern Luzon, in the West Philippine Sea Plate, in Celebes Sea Basin, in most of Indochina, in the area to the northeast of Red River Fault Zone in Vietnam. Lower group velocity shows up in central Philippine Island, in the southern margin of the South China Sea, in Palawan, in Sulu Sea Basin, in eastern Borneo, in the Gulf of Tonkin of Vietnam, and in northern Burma.

Figure 8d shows the group velocity distribution map of Love wave for the period of $100 \mathrm{~s}$. Higher group velocity shows up in the South China Sea Basin, in Luzon, in West Phillipine Sea Plate, in most part of Indochina, in the area to the northeast of Red River Fault zone in Vietnam, in most of Indochina, in Celebes sea Basin, in Palawan Trough and in the northwestern part of Borneo. Lower group velocity shows up in central Philippine Island, in Palawan, in Reed Bank, in northwest Sulu Sea Basin, in eastern Borneo, in northwest Sumatra, and in northern Burma.

Figures $9 \mathrm{a}-\mathrm{f}$ show the distribution of the shear wave velocity at the depth of $20,30,60$, 85,120 , and $200 \mathrm{~km}$, respectively. These distributions are obtained by inverting the regionalized group velocity dispersion curves of the fundamental mode Rayleigh and Love waves together.

Figure 9a shows the distribution of the shear wave velocity at the depth of $20 \mathrm{~km}$. The regions with higher shear wave velocity are the South China Sea Basin, the West Philippine Sea Plate, the southeastern part of Sulu Sea Basin, the Celebes Sea Basin, the area to the northeastern side of Red River Fault Zone. The regions with lower shear wave velocity are the Central Philippine Island, the Palawan Trough, the east Borneo and southeast of Borneo, the northwestern 
(a) profile 1, along latitude $18.5 \mathrm{~N}$

B. Indochina G.B. H. S.C.B. L. W.P.B.
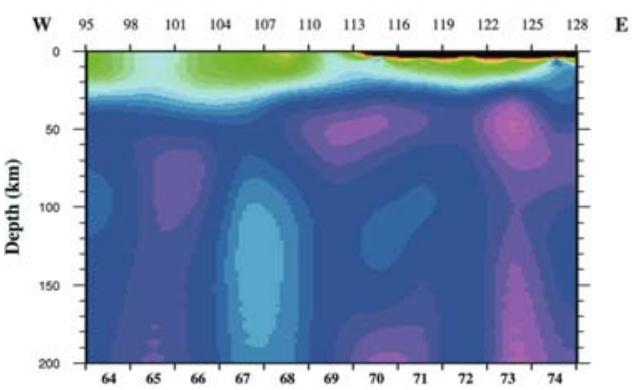

Shear wave velocity $(\mathrm{km} / \mathrm{sec})$

(b) profile 2, along latitude $15.5 \mathrm{~N}$

A.B. Indochina S.C.B. P.I. W.P.B.
.

$\begin{array}{llllllllllllll}\mathbf{W} & 95 & 98 & 101 & 104 & 107 & 110 & 113 & 116 & 119 & 122 & 125 & 128 & \mathbf{E}\end{array}$

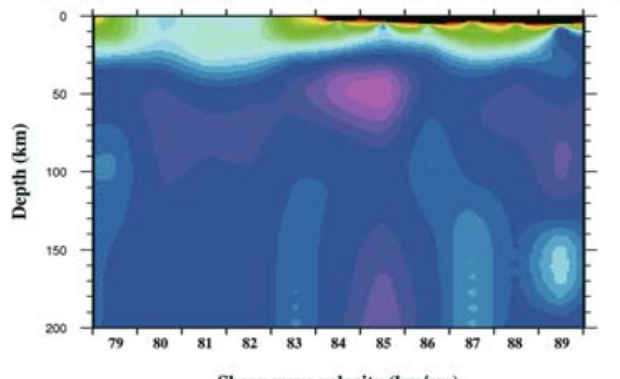

Shear wave velocity $(\mathrm{km} / \mathrm{sec})$

(c) profile 3, along latitude $12.5 \mathrm{~N}$

$$
\text { A.B. Indochina S.C.B. P.I. W.P.B. }
$$

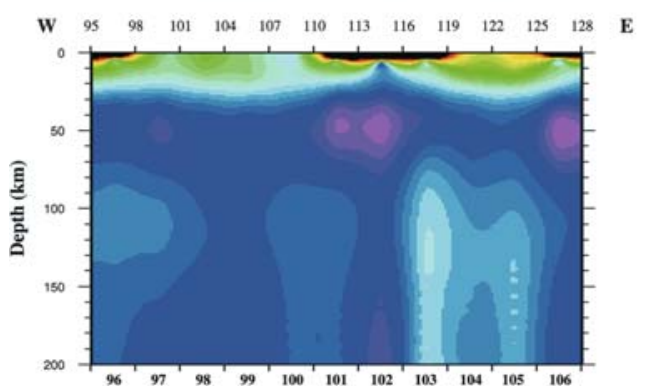

Shear wave velocity $(\mathrm{km} / \mathrm{sec})$ (d) Profile 4, along longitude 111.5 E

$$
\begin{array}{lll}
\text { S.S. Borneo } & \text { S.C.B. SE China }
\end{array}
$$

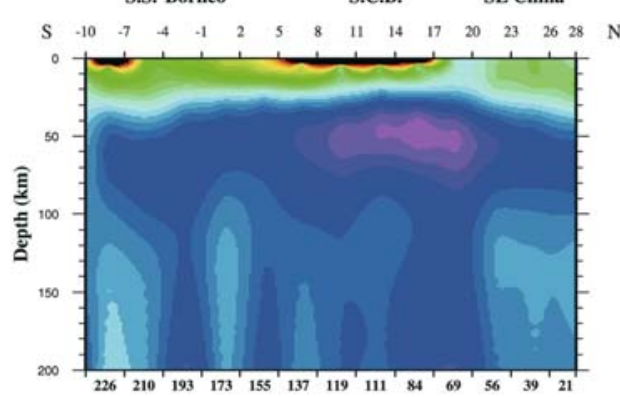

Shear wave velocity $(\mathrm{km} / \mathrm{sec})$

(e) Profile 5, along longitude 114.5 E

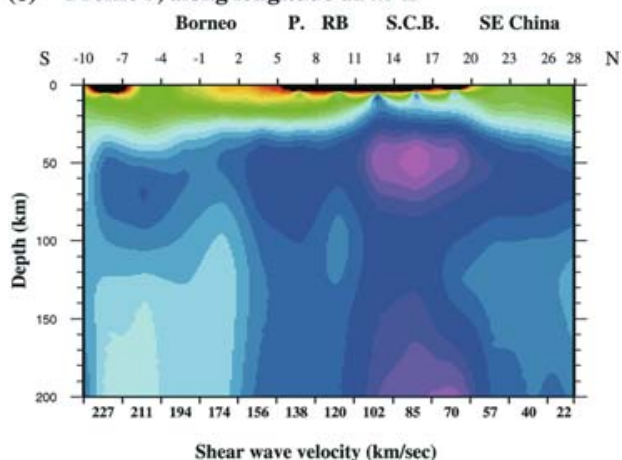

(f) Profile 6, along longitude 117.5 E
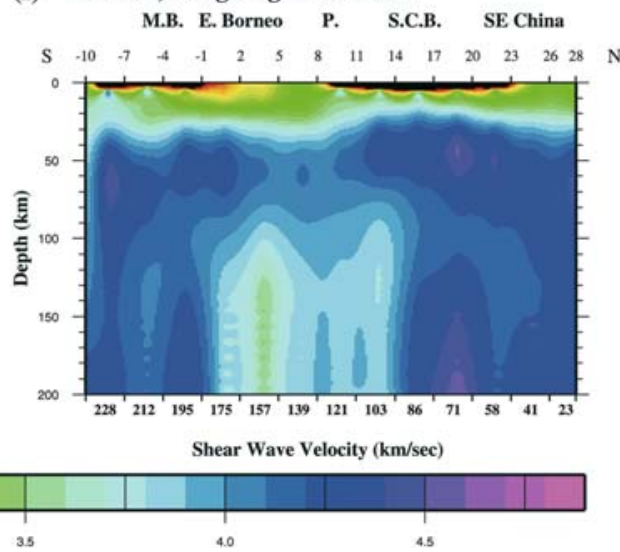

Figure 10. Vertical profiles for shear wave velocities of Figure 9 at different latitudes and longitudes. The locations of profiles are shown in Figure 9a. The abbreviations used are as follows: B.: Burma, G.B.: Gulf of Bacbo (Gulf of tonkin), H.: Hainan, S.C.B.: South China Sea Basin, L.: Luzon, W.P.B.: West Philippine Sea Basin, A.B.: Andaman Basin, P.I.: Philippine Islands, S.S.: Sunda Shelf, SE Chian: Southeast China, P.: Palawan Trough, RB: Reed Bank, E. Borneo: East Borneo.

Sumatra, the Molucca Sea, the northern Burma, and the Okinawa Trough.

Figure $9 \mathrm{~b}$ shows the distribution of the shear wave velocity at the depth of $30 \mathrm{~km}$. The regions with higher shear wave velocity are the South
China Sea Basin, the West Philippine Sea Plate, the northern Luzon and the area offshore to the northeast of Luzon, the Celebes Sea Basin, the area to the northeastern side of Red River Fault Zone in Vietnam, the northern part of the Gulf 

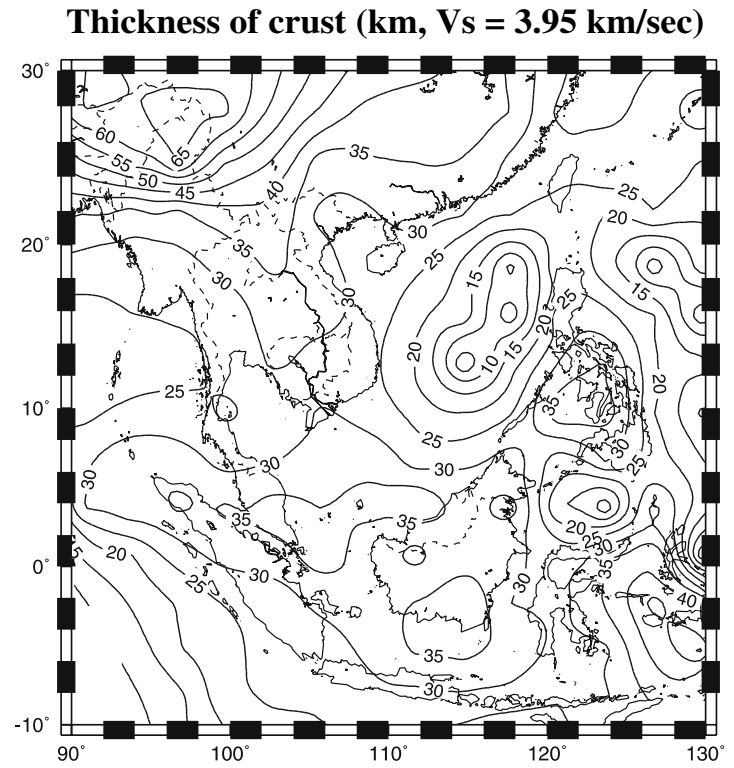

Figure 11. Contour lines of the thickness of crust $(\mathrm{km})$ in the South China Sea and its surrounding regions. We take $3.95 \mathrm{~km} / \mathrm{s}$ as velocity of $S_{n}$.

of Thailand, and part of northwestern Borneo. The regions with lower shear wave velocity are the Molucca Sea, the northern part of Burma, the Okinawa Trough, most of Indochina,

Thickness of Lithosphere (km)

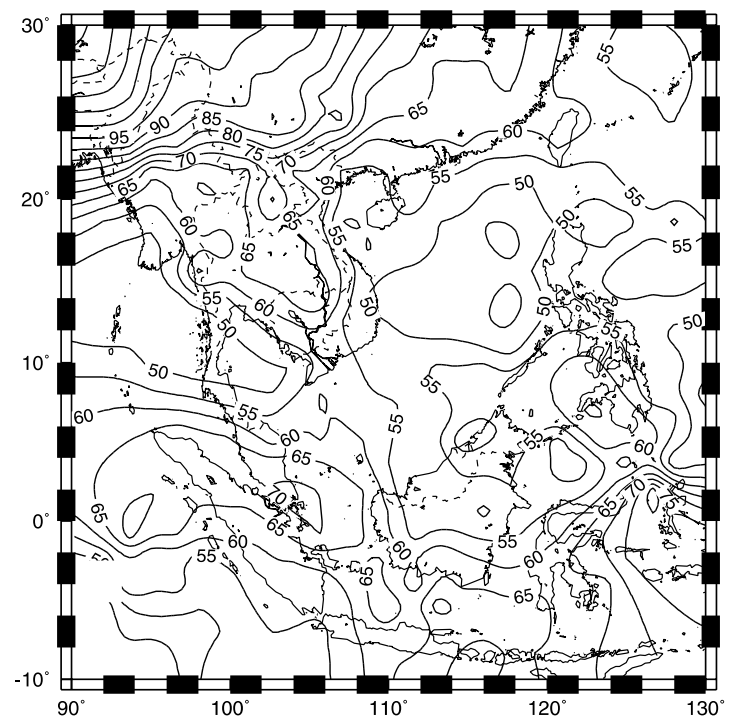

Figure 12. Contour lines of the thickness of lithosphere $(\mathrm{km})$ in the South China Sea and its surrounding regions. We take the depth where velocity of lid occurs as the thickness of lithosphere. the Philippine Islands, the Palawan, the Sulu Sea Basin, the Palawan Trough, eastern Borneo, and the northwestern Sumatra.

Figure 9c shows the distribution of the shear wave velocity at the depth of $60 \mathrm{~km}$. The regions with higher shear wave velocity are the South China Sea Basin, northern Luzon and the area offshore to the northeast of Luzon, the West Philippine Sea Plate, the Molucca Sea, Sulawesi, Thailand, the area in south China and north Vietnam to the northeastern side of Red-River Fault Zone in Vietnam. The regions with lower shear wave velocity are the Palawan, the northwest Sulu Sea Basin, eastern Borneo and the northern Burma.

Figure 9d shows the distribution of the shear wave velocity at the depth of $85 \mathrm{~km}$. The regions with higher shear wave velocity are the central South China Sea Basin, northern Luzon and the area offshore to the northeast of Luzon, the West Philippine Sea Plate, the Central Indochina, in the area of northern Vietnam and southern China to the northeastern side of the Red River Fault Zone in Vietnam, northwestern Sumatra, Natuna, Sulawesi, the Palawan Trough and the northwestern and western Borneo. The regions with lower shear wave velocity are the Central Philippine Islands, the Palawan, Reed Bank, the northwestern of Sulu Sea Basin, eastern Borneo and the northern Burma.

Figure 9e shows the distribution of the shear wave velocity at the depth of $120 \mathrm{~km}$. The regions with higher shear wave velocity are Luzon and the area offshore to northeast of Luzon, Central Thailand, the area in south China and northern Vietnam to the northeastern side of Red River Fault Zone in Vietnam, the South China Sea Basin, the Celebes Sea Basin, the Molucca Sea and the northern arm of Sulawesi, and the West Philippine Sea Plate. The regions with lower shear wave velocity are the Central Philippine Islands, the northern Burma, the southern margin of the South China Sea Basin, the Gulf of Tonkin of Vietnam and Hainan, the Palawan, Reed Bank, the Sulu Sea Basin, eastern Borneo, the Gulf of Thailand and the Andaman Sea, and Sumatra.

Figure 9f shows the distribution of the shear wave velocity at the depth of $200 \mathrm{~km}$. The regions with higher shear wave velocity are the South China sea Basin, the West Philippine Sea 
Table 1. The thickness of crust, the shear wave velocity of the lid of upper mantle and the thickness of lithosphere.

\begin{tabular}{llll}
\hline & $\begin{array}{l}\text { Thickness of } \\
\text { crust }(\mathrm{km})\end{array}$ & $\begin{array}{l}\text { Shear wave velocity } \\
\text { of lid }(\mathrm{km} / \mathrm{s})\end{array}$ & $\begin{array}{l}\text { Thickness } \\
\text { of lithosphere }(\mathrm{km})\end{array}$ \\
\hline South China Sea Basin & $5-10$ & $4.3-4.7$ & $45-50$ \\
Borneo & $30-35$ & $4.1-4.3$ & $55-65$ \\
Philippine Islands & $30-35$ & $4.2-4.3$ & $55-60$ \\
Sunda Shelf & $30-35$ & 4.3 & $55-65$ \\
Indochina & $25-40$ & $4.3-4.5$ & $55-70$ \\
Southeast China & $30-40$ & $4.0-4.3$ & $60-95$ \\
West Philippine Basin & $5-10$ & $4.7-4.8$ & $50-55$ \\
\hline
\end{tabular}

Plate, the area in south China and north Vietnam to the northeastern side of Red River Fault Zone in Vietnam, the area from southern Burma down southeastwards to Indochina and then to Natuna and western Borneo, the southeastern part of the Sulu Sea Basin, the Celebes Sea Basin, Molucca Sea and Sulawesi. The regions with lower shear wave velocity are the Central Philippine Islands, the Palawan, Reed Bank, the northwestern part of the Sulu Sea Basin, eastern Borneo, the northern Burma, and the Sumatra.

Figures 10a-f are the vertical profiles of shear wave velocity of the crust and upper mantle in South China Sea and its surrounding regions along attitudes $18.5^{\circ} \mathrm{N}, 15.5^{\circ} \mathrm{N}$, and $12.5^{\circ} \mathrm{N}$, and along longitudes $111.5^{\circ} \mathrm{E}, 114.5^{\circ} \mathrm{E}$, and $117.5^{\circ} \mathrm{E}$, respectively. The locations of these profiles are shown in Figure 9a with labels 1, 2, 3, 4, 5 and 6 , respectively. Shear wave velocities are obtained by inverting the regionalized group velocity dispersion curves of fundamental mode Rayleigh and Love waves together.

From these profiles, it is observed that there are significant lateral variations in the shear wave velocity structure, and these variations persists at least down to $200 \mathrm{~km}$ depth. Lateral variations of the crustal thickness and the lithospheric thickness are obvious. The shear wave velocity beneath the South China Sea Basin is higher than that of its adjacent region, but is lower than that of the West Philippine Basin. There are significant low-velocity zones of shear wave velocity in the upper mantle beneath the Gulf of Tonkin (Gulf of Bacbao), beneath northern Palawan, and beneath Borneo.

In Figure 11, the contour lines show lateral variations of the crustal thickness of the South
China Sea and its surrounding region. It shows that the crustal thickness of the northern South China Sea changes northwestward gradually from about $5 \mathrm{~km}$ at the central basin to about $30 \mathrm{~km}$ onshore of South China, and the crustal thickness of the southern South China Sea also increases steadily southeastward from about $5 \mathrm{~km}$ at the central basin to about $25 \mathrm{~km}$ at Palawan. We also observed that in the northern margin of South China Sea, the crustal structure beneath the western and eastern parts are very different. In South China, the crustal thickness increases westwards. It is about $30 \mathrm{~km}$ in the east coast and increases to about $65 \mathrm{~km}$ in eastern Tibet, closely similar to our previous finding (Tsai and $\mathrm{Wu}, 2000$ ). In Indochina, at the coast of Vietnam, it is about $25 \mathrm{~km}$, and increases northwestwards to about $40 \mathrm{~km}$. In the Philippine Islands, Borneo, and Peninsular Malaysia, the crustal thickness is about $30-$ $35 \mathrm{~km}$.

Figure 12 shows the distribution of thickness of the lithosphere in our study region. The lithospheric thickness in the South China Sea Basin is about $45-50 \mathrm{~km}$; in the West Philippine Basin is about $50-55 \mathrm{~km}$; in the Philippine Islands is about $55-60 \mathrm{~km}$; in Borneo is $55-$ $65 \mathrm{~km}$; in Sunda Shelf is about $55-65 \mathrm{~km}$; in Indochina is about $55-70 \mathrm{~km}$; in South China is about $60-95 \mathrm{~km}$. These results are summarized in Table 1.

From the corresponding contour lines of Figure 10 , we estimate the shear wave velocity of the lid in upper mantle. We take the maximum shear wave velocity in the upper mantle as the lid. The results are shown in Table 1. 


\section{Discussion}

In the interpretation of dispersion data, for the same period of group velocity Rayleigh wave will sample a deeper range than Love wave (Wu and Levshin, 1994; Ritzwoller et al., 1998). Therefore, a Love wave needs a longer period to sample the same depth as Rayleigh wave does. So, we can expect that the group velocity images of Rayleigh wave and of Love wave to be different. The shear wave velocity is obtained by inverting both the regionalized group velocities of Rayleigh and Love waves together.

The South China Sea Basin shows a high velocity region in the group velocity image of Rayleigh wave at the period of 16 s (Figure 7a) and of Love wave at the period of $20 \mathrm{~s}$ (Figure 8a). The group velocity image of Rayleigh wave at $16 \mathrm{~s}$ is related to the velocity structure at the depth of $16 \mathrm{~km}$. Thus, at the depth of $16 \mathrm{~km}$, the South China Sea Basin may have reached its upper mantle. This means that the South China Sea Basin may have crust of thickness less than $16 \mathrm{~km}$. Ludwig (1970) showed that the crust of the South China Sea Basin is oceanic. Our group velocity image map shows the same result. The South China Sea Basin shows higher group velocity image than that of its surrounding area. This is consistent with the structure of an extinct spreading ridge. The South China Basin was formed by sea floor spreading from 32 to $17 \mathrm{Ma}$ (Taylor and Hayes, 1980, 1983; Briais et al., 1993).

The southeastern part of the Sulu Sea Basin and Celebes Sea Basin also show higher velocity region in the group velocity image of Rayleigh wave at $16 \mathrm{~s}$ (Figure 7a) and of Love wave at $20 \mathrm{~s}$ (Figure 8a). This probably indicates that these two regions also have thinner crust. Murauchi et al. (1973) showed by seismic exploration that the Sulu Sea Basin is divided by Cagayan Ridge into two parts; the Northwest Basin and the Southeast Basin, and the crust of the Southeast Basin is oceanic. The Celebes Sea Basin has an oceanic crust of middle to late Eocene age (Weissel, 1980). Thus, our result is also consistent with that of the previous studies.

The wave velocities on the two sides of the Red River Fault Zone in Vietnam are different as can be seen on the group velocity image of Love wave at the period of $40 \mathrm{~s}$ (Figure $8 \mathrm{~b}$ ). The velocity on the northeastern side is higher than that on the southwestern side. This difference can also be seen on the group velocity images of Rayleigh wave at the periods of 28,40 and $50 \mathrm{~s}$ and of Love wave at the period of 28, 40, 50 and $60 \mathrm{~s}$. Thus, it is plausible that the Red River Fault Zone is a deep fault zone.

Most of Burma shows lower velocity on the group velocity images of Rayleigh (at the periods of 40 and $80 \mathrm{~s}$, i.e. Figures $7 \mathrm{~b}$ and c) and Love waves (at the periods of 40 and $80 \mathrm{~s}$, i.e. Figures $8 \mathrm{~b}$, and $\mathrm{c})$. This is probably due to the fact that Burma is located at the collision zone between Indian Plate and Eurasian Plate, so it is under compressional deformation and thus also have intense seismicity (Chen and Molnar, 1990). It is shown that before the arrival of continental India, there was an easterly dipping Benioff zone, reaching a depth of about $150 \mathrm{~km}$ beneath the Burman Volcanic Arc. With the arrival of continental India, the Benioff zone has become diffused and the whole region underlying the Indo-Burman Ranges and the central valley of Burma is now transformed into a collision zone characterized by right-slip motion, following extinction of the subduction-related volcanic arc (Hutchison, 1989).

The Philippine Islands shows a lower velocity region in the group velocity images of Rayleigh wave at the periods from $16 \mathrm{~s}$ to $40 \mathrm{~s}$ (Figures $7 \mathrm{a}, \mathrm{b}$ ) and of Love wave at the periods from 20 to $40 \mathrm{~s}$ (Figures $8 \mathrm{a}$ and $\mathrm{b}$ ) and also $50 \mathrm{~s}$. The Philippine archipelago, which comprises the western margin of the Philippine Sea between $5^{\circ} \mathrm{N}$ and $20^{\circ} \mathrm{N}$, separates the Philippine Sea Basin from the South China, Sulu, Celebes seas marginal basins. Like other convergent plate boundaries, the archipelago is characterized by high seismicity, Quaternary volcanism, and intense recent deformation (Hamburger et al., 1983). This is probably the reason that the Philippine Islands had lower velocity.

There is significant lateral heterogeneity in the shear wave velocity structure of the crust and upper mantle in the South China Sea and its surrounding area. This is shown in Figure 9. This lateral heterogeneity persists down to depth of at least $200 \mathrm{~km}$. Some surface features also have its effects down to depth of at least $200 \mathrm{~km}$, such as the South China Sea Basin, Borneo, Indochina, 
Table 2. The shear wave velocity of the lid of upper mantle and the thickness of lithosphere in each structure unit in the South China Sea region as obtained by Cao et al. (2001).

\begin{tabular}{lcl}
\hline & Shear velocity of lid $(\mathrm{km} / \mathrm{s})$ & Thickness of lithosphere $(\mathrm{km})$ \\
\hline South China Sea & $4.4(4.3-4.7)$ & $60-65(45-50)$ \\
Borneo & $\sim 4.4(4.1-4.3)$ & $60(55-65)$ \\
Philippine Islands & $\sim 4.4(4.2-4.3)$ & $65(55-60)$ \\
Indochina & $\sim 4.4(4.3-4.5)$ & $70(55-70)$ \\
Southeast China & $\sim 4.4(4.0-4.3)$ & $70-100(60-95)$ \\
West Philippine Basin & $4.55(4.7 \cdot 4.8)$ & $60(50-55)$ \\
\hline
\end{tabular}

The values in parenthesis are results of our study.

the Central Philippine Islands, the Sulu Sea Basin, the Gulf of Tonkin of Vietnam.

From Figure 9, the South China Sea Basin shows a higher velocity region begin at depth of $20 \mathrm{~km}$, and persists until depth of about $60 \mathrm{~km}$, but at depth of $65 \mathrm{~km}$, the shear wave velocity of the South China Sea Basin already decreases to a lower value. This plausibly indicates that the thickness of the lithosphere of the South China Sea Basin is less than $65 \mathrm{~km}$.

The Red River Fault Zone (RRFZ) is a major fault zone of our study area. We observed on the shear wave velocity distribution map that the shear wave velocities are different on the two sides of RRFZ. The northeast side of RRFZ has higher shear wave velocity. This difference is observed at depth of $20 \mathrm{~km}$, and persists to depth of $200 \mathrm{~km}$. This probably shows that the RRFZ has cut through the whole lithosphere and is plausibly a boundary between the South China block and the Indosinia Block. In north Vietnam, the Song Chay-Song Ma belt is the suture zone between the South China Block and the Indosinia block. By the end of the lower Palaeozoic, the Indosinia Block was consolidated onto the Cathaysian Plate (Hutchison, 1989). But it was proposed by earlier workers (Tapponnier et al., 1982; Briais et al., 1993) that during Tertiary Indochina was extruded along the Red River Fault Zone with a left-lateral displacement of probably 500-600 km. So, it looks like now the Red River Fault Zone is the boundary between the South China Block and the Indosinia Block. The Bacbo province in northern Vietnam (i.e. the region to the northeast of RRFZ in Vietnam) is a continental crustal extension of the South China Platform.

The central Philippine Islands is always showing lower shear wave velocity in the shear wave velocity distribution map or lower group velocity in the group velocity image map. This may be because of recent volcanism in the central Philippines. Recent volcanism occurs along two principal north-south chains, which are distributed from southern Luzon to the northern part of Mindanao (Divis, 1980). Another reason is that the Philippine Archipelago is a convergent plate boundary separating the Philippine Sea Basin from the South China, Sulu, Celebes Seas marginal basins, so the archipelago is characterized by high seismicity, Quaternary volcanism and intense recent deformation (Hamburger et al., 1983). This will make its velocity lower.

The Sulu Sea Basin always has lower shear wave velocity in Figure 9. The reason for having lower shear wave velocity in Sulu Sea Basin is probably related to its high heat flow (Murauchi et al., 1973). It was pointed out that the average of three heat flow measurements in the Sulu Sea is $2.4 \mathrm{HFU}$, which is markedly higher than the average heat flow of $1.3 \mathrm{HFU}$ of all ocean basins.

In Figure 9a, the areas to the northwest and southeast of Borneo have lower shear wave velocity. This is consistent with the distribution of Paleogene and Neogene sediment in the northwest and southeast part of Borneo (Figure 3.8 in Hutchison, 1989).

In Figure 9, in northwestern Borneo, relatively higher shear wave velocity begins to show up at depth of $30 \mathrm{~km}$, and persists to depth of $70 \mathrm{~km}$. This is probably the subduction zone of the pre-South China Sea Basin, which was suggested to exist southeast of Reed Bank prior to its subduction beneath Borneo (Taylor and Hayes, 1980). This higher shear wave velocity zone extends westwards to about $110^{\circ} \mathrm{E}$. This is consistent with the suggestion of Ludwig et al. (1979) that the Palawan Trough possibly extends westwards to about $110^{\circ} \mathrm{E}$. 


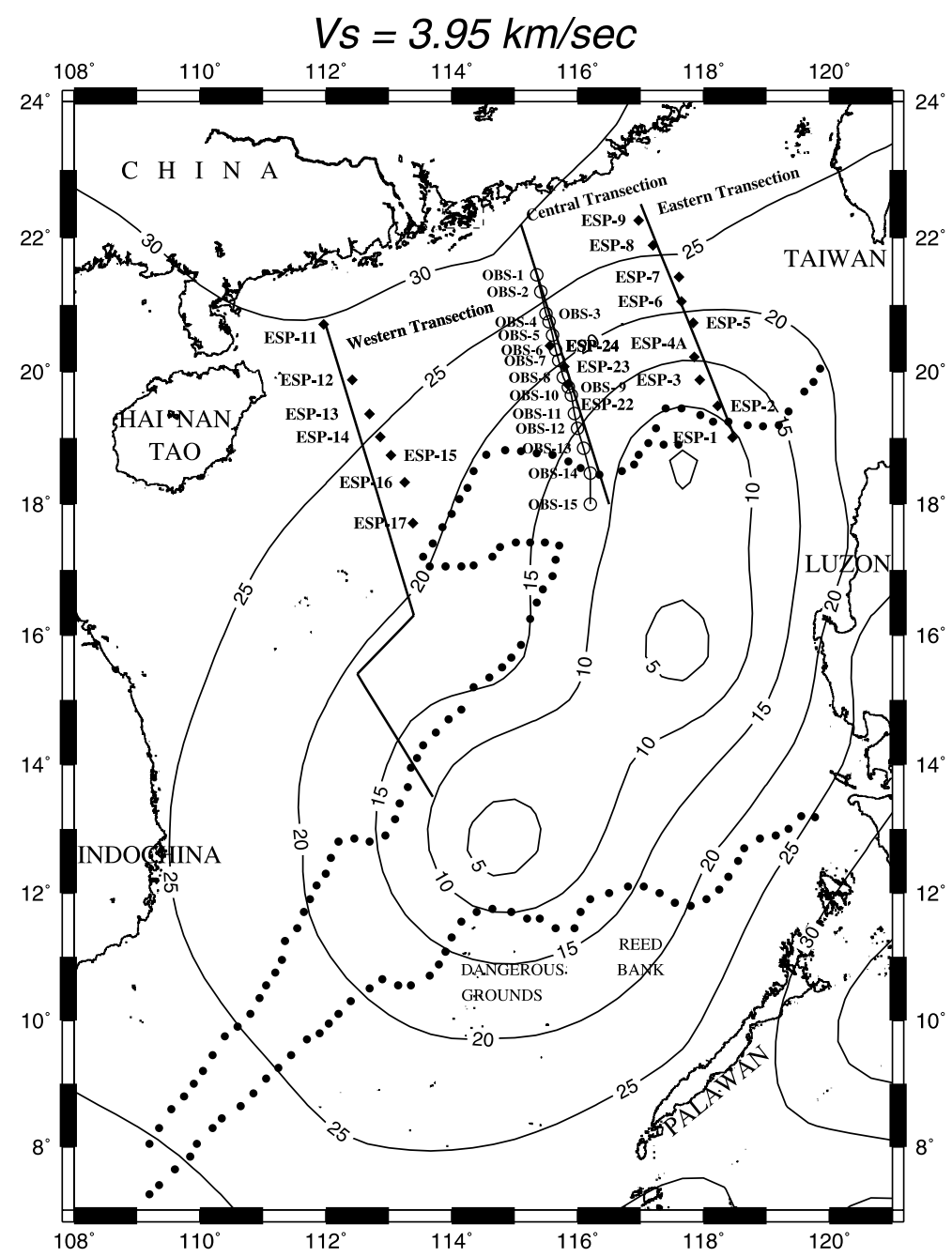

Figure 13. Contour lines of the crustal thickness $(\mathrm{km})$ in the South China Sea region. Heavy dotted line represents the inferred continent-ocean boundary (COB) (from Nissen et al., 1995b). Heavy lines are the locations of the three transects of Nissen et al. (1995b). Open circles are locations of OBS of Yan et al. (2001). Diamonds are locations of ESPs of Nissen et al. (1995a).

In Figure 9, higher shear wave velocity of the northern arm of Sulawesi begins to show up at depth of $60 \mathrm{~km}$. This higher shear wave velocity expands towards the Celebes Basin and persists down to about $200 \mathrm{~km}$. This is probably the westward subduction of Molucca Sea Plate. The Molucca Sea Plate is subducting eastards under the Hamahera island arc and simultaneously is subducting westwards under Sangihe island arc. Cardwell et al. (1980) has shown that the Sangihe Island Arc is an east-facing island arc system where lithosphere of Molucca Sea Plate has been subducted to the west beneath the Sangihe Arc. The seismic zone dips west from the center of the Molucca Sea to a maximum depth of $682 \mathrm{~km}$ beneath the Celebes Basin (Cardwell et al., 1980). This can be seen from Figures $9 \mathrm{c}-\mathrm{f}$.

In Figure 9, northern Burma has lower shear wave velocity all the way from depth of $20 \mathrm{~km}$ down to depth of $200 \mathrm{~km}$. This is possibly due to deformation caused by collision between the Eurasian plate and the Indian Plate.

In Figure 9, higher shear wave velocity shows up in the western part of Indochina (southern Thailand) at depth of $50 \mathrm{~km}$. This higher shear wave velocity zone becomes bigger at deeper depth, and persists down to depth of $200 \mathrm{~km}$. 
This is probably a cooler plate, which was moved southeastwards accompanying the southeastwards extrusion of Indochina as a result of collision between the Indian Plate and the Eurasian Plate.

From Figure 9, northern Luzon begins to show higher shear wave velocityat depth of $30 \mathrm{~km}$, and persists down to depth of about $85 \mathrm{~km}$. This is probably the subduction of West Philippine Basin along the East Luzon Trough. The East Luzon Trough occurs along the east coast of Luzon and is defined by a bathymetric depression greater than $5.2 \mathrm{~km}$ depth fromabout $17^{\circ} \mathrm{N}$ to $15^{\circ} \mathrm{N}$. A seismiczone dipping to the west has developed to a depth of about $85 \mathrm{~km}$ beneath the east coast of Luzon (Hamburger et al., 1983).

Cao et al. (2001) used surface waveform inversion to get a three-dimensional shear wave velocity structure of crust and upper mantle in South China Sea and its adjacent regions. Their result shows significant difference in the velocity distribution, especially in the shear wave velocity in the lid of upper mantle and the thickness of lithosphere. Their results are summarized in Table 2, for easy comparison we put our results on Table 2 inside the parenthesis.

Tables 1 and 2 show that our results are similar to those of Cao et al. (2001). As expected, our estimated thickness of the lithosphere is smaller than that of Cao et al. (2001).

In Figure 13, we overlay the locations of the three transects (Eastern Transect, Central Transect and Western Transect) of Nissen et al. (1995b) and the centers of Expanding Spread Profile (ESP) of Nissen et al. (1995a). At these 20 ESPs, they got velocity-depth information and at 17 locations of the 20 ESPs they got reliable depths to the Moho and the corresponding crustal thickness. They concluded, for both the Eastern and Western Transects, these values reveal a general decrease in crustal thickness southward across the China margin. Nissen et al. (1995b) used the gravity data constrained by the results of ESPs to deduce the large-scale crustal variations across the three transects. The result shows that along all these three transects the crustal thickness increases from the South China Sea Basin to onshore of South China and that the extended crust in the west covers approximately twice the horizontal distance of that in the east. From Figure 13, at the Eastern Transect, our result shows that the crustal thickness increases from about $10 \mathrm{~km}$ in the South China Sea Basin to about $27 \mathrm{~km}$ in the South China continental shelf. Correspondingly, at the Central Transect the crustal thickness increases from about 10 to $30 \mathrm{~km}$, and at the Western Transect it varies from about 10 to $30 \mathrm{~km}$. Our result also shows that the extended crust is wider in the west than in the east. So, the main features of our result are consistent with those of Nissen et al. (1995b).

We also overlay the positions of OBS (OceanBottom Seismograph) of Yan et al. (2001) in Figure 13. The results of Yan et al. (2001) showed that the South China continental shelf (OBS-1 and OBS-2) has a crustal thickness of $22 \mathrm{~km}$, the upper slope (OBS-3-OBS-8) also has a crustal thickness of $22 \mathrm{~km}$, for the lower slope (OBS-9-OBS-13) the crustal thickness varies from 21 to $9 \mathrm{~km}$, and at the ocean basin (OBS-14 and OBS-15) the crustal thickness is $8 \mathrm{~km}$. The crustal thickness observed by Yan et al. (2001) in the South China continental margin decreases from $22 \mathrm{~km}$ at South China continental shelf to $8 \mathrm{~km}$ at the South China Sea Basin. Our corresponding results are as follows: the South China continental shelf (OBS-1 and OBS-2) has a crustal thickness of about 27-26 km, the upper slope (OBS-3-OBS-8) has a crustal thickness varies from 24 to $19 \mathrm{~km}$, for the lower slope (OBS-9-OBS-13), the crust thickness varies from 18 to $13 \mathrm{~km}$, and at the ocean basin (OBS-14 and OBS-15), the crust thickness varies from 12 to $11 \mathrm{~km}$. By comparing the estimations of Yan et al. (2001) with ours, we find that the gross feature is consistent, that is over the northern margin of the South China Sea the thickness of crust decreases from the South China continental shelf towards the South China Sea Basin.

Xia et al. (1994) show that the mainland of South China is underlain by continental crust with thickness of $30 \mathrm{~km}$ in Fuzhou-Guanzhou, $27-28 \mathrm{~km}$ in Xiameng-Shantou, 27-29 km in the north of Hainan Island. This shows that in the east coast of Southeast China the crustal thickness is $27-30 \mathrm{~km}$. Our estimate is consistent with this result of Xia et al. (1994). Schlüter et al. (1996) shows results of seismic profiles along some locations, some of the results show the crustal thickness. For example, the crustal thickness in the eastern South China Sea Basin varies from 9 to $12 \mathrm{~km}$, the crustal thickness of the Reed Bank Terrane varies from 22 to $27 \mathrm{~km}$. This is consistent with that of our result also. Li 
and Mooney (1998) show the distribution of crustal thickness in China by analyzing the result of Deep Seismic Sounding in China. The map shows the crustal thickness in the east coast is about $30 \mathrm{~km}$ and increases westwards to about $70 \mathrm{~km}$ in Tibet. This is also consistent with that of our present and previous results (Tsai and $\mathrm{Wu}, 2000$ ). Kido et al. (2001) shows that in the northern South China Sea, the crustal thickness thins seawards from approximately $22 \mathrm{~km}$ beneath the continental shelf to $5 \mathrm{~km}$ beneath the main basin. This trend is similar to that of our result. Qiu et al. (2001) shows the crust structure across the Xisha Trough. Although, our resolution cannot resolve the detailed structure of Xisha, but their trend of increasing in crustal thickness from $8 \mathrm{~km}$ beneath the Xisha Trough to $25 \mathrm{~km}$ under the coast line of Southeast China is similar to that of our result.

In summary, in the northern margin of the South China Sea, our estimation of crustal thickness derived from the group velocity dispersion characteristics of the fundamental mode Rayleigh waves are consistent with that of previous works (Xia et al., 1994; Nissen et al., 1995a, b; Schlüter et al., 1996; Li and Mooney, 1998; Tsai and $\mathrm{Wu}$, 2000; Kido et al., 2001; Yan et al., 2001; Qiu et al., 2001).

\section{Conclusion}

We have used the long period or broadband seismograms from 1252 earthquakes that occurred in Southeast Asia to calculate the dispersion curves of fundamental mode Rayleigh and Love waves. A three-dimensional shear wave velocity model of the crust and upper mantle in South China Sea and its surrounding regions is therefore obtained. Our conclusions are as follows:

(1) There is significant heterogeneity in the distribution of group velocity of fundamental mode Rayleigh and Love waves in the South China Sea and its surrounding regions. The South China Sea Basin has higher group velocity than its adjacent regions at the periods of 16, 20, 40, 80, and $100 \mathrm{~s}$. Different structure units show different group velocities on the image map.
(2) There is significant heterogeneity in shear wave velocity structure of the crust and upper mantle in the South China Sea and its surrounding regions. The thickness of crust, the shear wave velocity of the lid in upper mantle and the thickness of lithosphere are significantly different among different structure units.

(3) The thickness of crust in South China Sea Basin is about $5-10 \mathrm{~km}$; in Indochina 25$40 \mathrm{~km}$; in Peninsular Malaysia $30-35 \mathrm{~km}$; in Borneo $30-35 \mathrm{~km}$; in Palawan $35 \mathrm{~km}$; in Philippine Islands $30-35 \mathrm{~km}$, in Sunda Shelf 30-35 km, in Southeast China $30-40 \mathrm{~km}$, in West Philippine Basin 5-10 km.

(4) The South China Sea Basin has a lithosphere with thickness of about $45-50 \mathrm{~km}$, and its shear wave velocity of lid is about 4.3$4.7 \mathrm{~km} / \mathrm{s}$; Indochina has a lithosphere with thickness of about $55-70 \mathrm{~km}$, and its shear wave velocity of lid is about $4.3-4.5 \mathrm{~km} / \mathrm{s}$; Borneo has a lithosphere with thickness of about $55-65 \mathrm{~km}$, and its shear wave velocity of lid is about $4.1-4.3 \mathrm{~km} / \mathrm{s}$; the Philippine Islands has a lithosphere with thickness of about $55-60 \mathrm{~km}$, and its shear wave velocity of lid is about $4.2-4.3 \mathrm{~km} / \mathrm{s}$; West Philippine Basin has a lithosphere with thickness of about $50-55 \mathrm{~km}$, and its shear wave velocity of lid is about $4.7-4.8 \mathrm{~km} / \mathrm{s}$; Sunda Self has a lithosphere with thickness of about 55 to 65 $\mathrm{km}$, and its shear wave velocity of lid is about $4.3 \mathrm{~km} / \mathrm{s}$.

(5) The Red-River Fault Zone is inferred to be a deep-seated fault zone. It probably has penetrated to a depth of at least $200 \mathrm{~km}$. Both sides of RRFZ have different shear wave velocity. The northeast side has higher shear wave velocity. It is suggested to be the boundary between the South China Block and the Indosinia block.

\section{Acknowledgements}

We thank the National Science Council for funding this research under the contract number NSC 91-2116 -M-008-010. We also thank Mr. Trinh Viet Bac of the Institute of Geological Sciences, National Center for Natural Sciences and Technology, Hanoi, Vietnam, for helping the data 
collection at Bacgiang and Vinh City, Vietnam. We thank Dr. Shu-Kun Hsu for valuable suggestions and help. We also thank Dr. Ruey-Der $\mathrm{Hu}-$ ang for valuable help.

\section{References}

Briais, A., Patriat, P. and Tapponnier, P., 1993, Updated interpretation of Magnetic Anomalies and seafloor spreading stages in the south China sea : Implications for the Tertiary Tectonics of Southeast Asia, J. Geophys. Res. 98, 6299-6328.

Cao, X.-L., Zhu, J.-H, Zhao, L.-F., Cao, J.-M. and Hong, X.-H., 2001, Three dimensional shear wave velocity structure of crust and upper mantle in south china sea and its adjacent regions by using surface waveform inversion, Acta Seismologica Sinica 23, (2).

Cardwell, R. K., Isacks, B. L. and Karig, D. E. 1980, The spatial distribution of earthquakes, focal mechanism solutions, and subducted lithosphere in the Philippine and Northeastern Indonesian islands, in Hayes, D. E. (ed.), The Tectonic And Geologic Evolution Of Southeast Asian Seas and Islands, Geophys. Monogr. 23, 1-35. Washington, D.C. American Geophysical Union.

Chen, B. and Lei, S., 1987, Map of crustal structures, in He, L. and Chen, B. (eds.), Atlas of Geology and geophysics of South China Sea, China: Map Publishing House of Guangdong Province, p. 10.

Chen, W.-P. and Molnar, P., 1990, Source parameters of earthquakes and intraplate deformation beneath the Shillong Plateau and the northern Indoburman Ranges, J. Geophys. Res. 95, 12527-12552.

Constable, S. C., Parker R. L. and Constable, C. G., 1987, Occam's inversion: A practical algorithm for generating smooth models from electromagnetic sounding data, Geophysics 52, 289-300.

Divis, A. F., 1980, The petrology and tectonics of recent volcanism in the Central Philippine Islands, in Hayes, D. E. (ed.), The Tectonic and Geologic Evolution Of Southeast Asian Seas and Islands, Geophys. Monogr. 23, 127-144. Amer. Geophys. Union, Washington, D.C.

Dziewonski, A., Bloch, S. and Landisman, M. 1969, A technique for the analysis of transient seismic signals, Bull. Seism. Soc. Am. 59, 427-444.

Ewing, C. E. and Mitchell, M. M., 1970, Introduction to Geodesy, New York: American Elsevier Publishing Co., p. 304.

Hamburger, M. W., Cardwell R. K. and Isacks, B. 1983, Seismotectonics of the Northern Philippine Island Arc, in Hayes, D. E. (ed.), The Tectonic and Geologic Evolution of Southeast Asia Seas and Islands, Part 2, Geophys. Monogr. 27, 1-22, Washington, D.C.: American Geophysical Union.

Herrmann, R. B., 1973, Some aspects of band-pass filtering of surface waves, Bull. Seism. Soc. Am. 63, 663-671.

Herrmann, R. B., 1991, Computer Program in Seismology, Vol. IV: Surface Wave Inversion, Saint Louis University: Department of Earth and Atmospheric Sciences.

Hutchison, C. S., 1989, Geological Evolution of South-east Asia, Oxford: Clarendon Press, p. 368.

Kido, Y., Suyehiro, K. and Kinoshita, H., 2001, Rifting to Spreading Process along the Northern Continental margin of the South China Sea, Marine Geophys. Res. 22: 1-15, 2001.
Knopoff, L., 1969, Phase and group slowness in inhomogeneous media, J. Geophys. Res. 74, 1701.

Li, S.-L. and Mooney, W.D., 1998, Crustal structure of China from deep seismic sounding profiles, Tectonophysics 288, $105-113$.

Liu Fu-Tian, Wu Hua, Liu Jian-Hua, $\mathrm{Hu}$ Ge, Li Qiang and quke-Xin, 1990, 3-D velocity images beneath the Chinese continent and adjacent regions, Geophys. J. Int. 101, 379394.

Liu, Z., Wang, Q., Yuan, H., Su, D., 1985, The Bouguer anomalies and depths of Mohorovicic discontinuity in the South China Sea region, Bull. Chin. Oceanogr. 4, 579-590.

Ludwig, W. J., Kumar, N. and Houtz, R. E., 1979, Profilersonobuoy measurements in the south China sea basin, J. Geophys. Res. 84, 3505-3518.

Ludwig, W. J., 1970, The Manila trench and west Luzon Trough, III, seismic-refraction measurements, Deep Sea Res. 17, 553-571.

Menke, W., 1984, Geophysical Data Analysis: Discrete Inversion Theory, San Diego: Academic, 260pp.

Moore, G. F., Curray, J. R., Moore, D. g. and Karig, D. E., 1980, Variations in geologic structure along the Sunda Fore Arc, Northeastern Indian ocean, in Hayes, D. E. (ed.), The Tectonic and Geologic Evolution of Southeast Asian Seas and Islands, Geophys. Monogr. 23, 145-160, American Geophysical Union, Washington, D.C.

Murauchi, S., Ludwig, W.J., Den, N., Hotta, H., Asanuma, Yoshii, T., Kubotera, A. and Hagiwara, K., 1973, Structure of the Sulu sea and the celebes sea, J. Geophys. Res. 78, 3437-3447.

Nishimura, C. E. and Forsyth, D. W., 1985, Anomalous Love-wave phase velocities in the Pacific: Sequential purepath and spherical harmonic inversion, Geophys. J. r. astr. Soc. 81, 389-407.

Nissen, S. S., hayes, D. E., Buhl, P. and Diebold, J., Yao Bochu, Zeng Weijun and chen Yongqin, 1995a, Deep penetration seismic soundings across the northern margin of the south China Sea, J. Geophys. Res. 100(B11), 22, 407422,433

Nissen, S. S., Hayes, D. E., Yao, B., Zeng W., Chen Y. and $\mathrm{Nu}$ X., 1995b, Gravity, heat flow, and seismic constraints on the processes of crustal extension: Northern Margin of the South China Sea, J. Geophys. Res. 100(B11), 22, 447422, 483.

Parke, M. K., Emery, K. O., Szymankiewicz, R. and Reynolds, L. M. 1971, Structural framework of continental margin of South China Sea, Am. Assoc. Proc. Geol. Bull. 55, 723-751.

Qiu, X., Ye, S., Wu, S., Shi, X., Zhou, D., Xia, K., Flueh, E. r., 2001, Crustal structure across the Xisha Trough, northwestern South China sea, Tectonophysics 341, 179-193.

Ritzwoller, Michael H. and anatoli L. Levshin, 1998, Eurasian surface wave tomography: Group velocities, J. Geophys. Res. 103, 4839-4878.

Rodi, W. L., Glover, P. Li, T. M. C. and Alexander, S. S., 1975, A fast, accurate method for computing group velocity partial derivatives for Rayleigh and Love modes, Bull. Seism. Soc. Am. 65, 1105-1114.

Ryall, J. C., 1982, Some thoughts on the crust structure pf Peninsular Malaysia - results of a gravity traverse. Geological soc. Malaysia bull. 15, 9-18.

Schlüter, H. U., Hinz, K. and Block, M., 1996, Tectonostratigraphic terranes and detachment faulting of the South China Sea and Sulu Sea, Marine Geol. 130, 39-78. 
Steinhart, J. S., 1967, Mohorovičič discontinuity, in Runcorn, K. (ed.), International Dictionary of Geophysics, vol. 2, pp. 991-994, Tarrytown, N.Y.: Pergamon.

Tapponnier, P., Peltzer, G., Armijo, R., Le Dain, A. Y. and Cobbold, P., 1982, Propagating extrusion tectonics in Asia: New insights from simple experiments with plasticine, Geology 10, 611-616.

Taylor, B. and Hayes, D. E., 1980, The tectonic evolution of the South China Basin, in Hayes, D. E. (ed.), The Tectonic and Geologic Evolution of Southeast Asian Seas and Islands, Geophys. Monogr. 23, 89-104, Washington D.C.: American Geophysical Union.

Taylor, B. and Hayes, D. E., 1983, Origin and history of the south China sea, In Hayes, D. E. (ed.), The tectonic and Geologic Evolution of Southeast Asia seas and Islands, Part 2; Geophys. Monogr. 27, 23-56, Washington, D.C.: American Geophysical Union.

Tsai, Y.-B. and Wu, H.-H., 2000, S-wave velocity structure of the crust and upper mantle under southeastern China by surface wave dispersion analysis, J. Asian Earth Sci. 18, 255-265.
Twomey, S., 1977, Introduction to the Mathematics of Inversion in Remote Sensing and Indirect Measurement, Elsevier Scientific Pub. Co., 243pp.

Weissel, J. K., 1980, Evidence for eocene oceanic crust in the celebes basin, in Hayes, D. E. (ed.), The Tectonic and Geologic Evolution of Southeast Asian Seas and Islands, Geophys. Monogr. 23, 37-48, Washington D.C.: American Geophysical Union.

Wu, F. T. and Levshin, A., 1994, Surface-wave group velocity tomography of East Asia, Phys. Earth and Planetary Interiors 84, 59-77.

Xia, K.-Y., Huang, C.-L, Jiang, S.-R, Zhang, Y.-X. and Su, D.-Q., 1994, Comparison of the tectonics and geophysics of the major structural belts between the northern and southern continental margins of the South China Sea, Tectonophysics 235, 99-116.

Yan, P., Zhou D. and Liu, Z., 2001, A crustal structure profile across the northern continental margin of the South China Sea, Tectonophysics 338, 1-21. 